\title{
The effects of three different exercise modalities on markers of male reproduction in healthy subjects: a randomized controlled trial
}

\author{
Behzad Hajizadeh Maleki ${ }^{1}$, Bakhtyar Tartibian² and Mohammad Chehrazi ${ }^{3}$ \\ ${ }^{1}$ Department of Sports Medicine, Justus-Liebig-University, Giessen, Germany, ${ }^{2}$ Department of Sport Injuries, Faculty \\ of Physical Education and Sport Sciences, Allameh Tabataba'i University, Tehran, Iran, and ${ }^{3}$ Department of \\ Epidemiology and Reproductive Health, Reproductive Epidemiology Research Center, Royan Institute for \\ Reproductive Biomedicine, ACECR, Tehran, Iran
}

Correspondence should be addressed to B Hajizadeh Maleki; Email: hajizadeh.sci.phys@gmail.com or behzad.hajizadehmaleki@sport.uni-giessen.de

\begin{abstract}
The aim of this study was to investigate the effects of moderate-intensity continuous training (MICT), high-intensity continuous training (HICT) and high-intensity interval training (HIIT) on markers of male reproduction including seminal markers of oxidative stress and inflammation as well as semen quality and sperm DNA integrity in healthy human subjects. A total of 397 healthy male volunteers were screened and 280 were randomly assigned to one of the MICT $(n=70)$, HICT $(n=70)$, HIIT $(n=70)$ and non-exercise (NON-EX, $n=70$ ) groups. Subjects had inflammatory markers (IL-1 $\beta$, IL-6, IL-8 and TNF- $\alpha$ ), oxidants (ROS, MDA and 8-isoprostane), antioxidants (SOD, catalase and TAC), semen parameters and sperm DNA damage measured at baseline $\left(T_{1}\right)$, the end of week $12\left(T_{2}\right)$, the end of week $24\left(\mathrm{~T}_{3}\right)$, and $7\left(\mathrm{~T}_{4}\right)$ and 30 days $\left(\mathrm{T}_{5}\right)$ after training. Chronic MICT, HICT and HIIT attenuated seminal markers of oxidative stress and inflammation with different kinetics for the three types of exercise $(P<0.05)$, and these changes were correlated with favorable improvements in semen quality parameters and sperm DNA integrity $(\boldsymbol{P}<0.05)$. MICT was superior to HICT and HIIT in the improvements of markers of male reproductive function $(P<0.05)$. In conclusion, different exercise modalities favorably affect markers of male reproduction with different kinetics, suggesting intensity-, duration- and type-dependent adaptations to exercise training in healthy human subjects.

Reproduction (2017) 153 157-174
\end{abstract}

\section{Introduction}

Human semen contains a variety of different cytokines and other immunological factors that may affect physiologic events underlying male reproductive function (Politch et al. 2007). Cytokines, at physiological concentrations, constitute natural components of the seminal plasma and are intrinsically involved in normal reproductive physiology (Fraczek \& Kurpisz 2015). However, local or systemic perturbations of these cytokines have been associated with poor semen quality and may be critically dangerous for sperm membranes and DNA integrity (Fraczek \& Kurpisz 2015). Some authors have also suggested that high levels of certain proinflammatory cytokines, including interleukin (IL)- $1 \alpha / \beta$, IL-8 and tumor necrosis factor alpha (TNF- $\alpha$ ) upregulate the expression of genes responsible for the redox system in semen (Naz \& Kaplan 1994, Fraczek \& Kurpisz 2007). In this sense, an increase in reactive oxygen species (ROS) generation by human sperm was observed after incubation of ejaculated spermatozoa with recombinant cytokines at pathological concentrations (Martinez et al. 2007, Fraczek et al. 2008). Under physiological conditions, ROS play an important role in normal physiological processes to ensure appropriate fertilization, but the same ROS under pathological conditions, may induce oxidative stress and can negatively influence the quality of spermatozoa and impair their overall fertilizing capacity (Fraczek et al. 2008). Oxidative stress has been identified as an area of great attention because of the fact that ROS and their metabolites can lead to largely irreversible perturbations of semen parameters and sperm DNA integrity. The consequences are poor fertilization, poor embryonic development, pregnancy loss, birth defects and childhood cancer (De luliis et al. 2006, Tremellen 2008, Aitken et al. 2010, Agarwal et al. 2014). To preserve cellular damage by overproduction of ROS, seminal plasma contains a number of enzymatic and non-enzymatic antioxidants, which act as free radical scavengers to eliminate surplus ROS and allow 
a balance between ROS generation and scavenging activity to be achieved. These antioxidants not only prevent these reactive species from being formed but also remove them before they can damage vital components of the sperm cell (Khosrowbeygi \& Zarghami 2007, Yousefniapasha et al. 2015).

Over the last decade, a number of studies have been published on the relevance and effects of physical exercise on reproductive function (Safarinejad et al. 2009, Tartibian \& Maleki 2012a,b, Tartibian et al. 2012, Hajizadeh Maleki et al. 2013, Maleki et al. 2014, 2016b, Hajizadeh Maleki \& Tartibian 2015). Previous studies have reported that strenuous exercise in the form of long-distance running and endurance cycling may be deleterious for sperm production (De Souza et al. 1994, Wise et al. 2011, Tartibian \& Maleki 2012b, Tartibian et al. 2012, Maleki et al. 2014, 2016b, Hajizadeh Maleki \& Tartibian 2015). In this sense, several studies from the author's group demonstrated that exercise-induced changes in seminal markers of oxidative stress and proinflammatory cytokines were negatively correlated with semen quality parameters and sperm DNA integrity (Tartibian \& Maleki 2012b, Maleki et al. 2014, 2016b, Hajizadeh Maleki \& Tartibian 2015). However, another theory supported by more recent evidence suggests that exercise might improve the semen quality (Tartibian \& Maleki 2012a, Hajizadeh Maleki et al. 2013, Gaskins et al. 2015). Data from recent studies in this context also consistently show an association between training status and markers of male reproduction (Tartibian \& Maleki 2012a, Hajizadeh Maleki et al. 2013). A recent study in our lab, for instance, showed that in young, healthy male volunteers, the higher levels of leisure-time physical activity were associated with better semen parameters and DNA integrity as well as lower pro-antioxidant ratio, whereas both vigorous-intensity physical activities and sedentary life style were associated with perturbations in sperm DNA integrity and redox homeostasis as well as poor semen parameters (Tartibian \& Maleki 2012a, Hajizadeh Maleki et al. 2013). These findings raise the hypothesis that the magnitude and permanence of reproductive response to exercise may differ with respect to factors such as type of exercise, magnitude of exercise exposure and the intensity of exercise protocol.

Although the modulating effects of exercise training on immunological and oxidative stress responses are widely recognized across body fluids, organs and tissues (Tartibian et al. 2011, 2015, Oh et al. 2013, Soares et al. 2015), its implementation remains challenging in the area of male reproduction. Furthermore, the efficacy of different types of exercise training is still elusive in this field. Up to now, there are also limited data about the influence of chronic exercise on markers of male reproduction. Hence, taken together, we carried out a randomized controlled trial to evaluate comparatively the effects of moderate-intensity continuous training
(MICT), high-intensity continuous training (HICT) and high-intensity interval training (HIIT) on markers of male reproduction including seminal markers of oxidative stress and inflammation as well as semen quality and sperm DNA integrity in healthy human subjects.

\section{Materials and methods \\ Ethical approval}

The research protocol was approved by the Human Subject Internal Review Board committee of the Urmia University of Iran.

\section{Experimental design and subjects}

A total of 397 healthy men (aged 25-40) were enrolled in this study. Preliminary screening included a medical history and physical examination by medical specialist in Urmia University outpatient clinic. Before the initiation of the study protocol, each subject also performed a Bruce treadmill test (Ergo XELG90 Spezial, Woodway, Weil am Rhein, Germany) to determine the maximal oxygen uptake $\left(\mathrm{VO}_{2 \max }\right)$. The initial speed and incline were $1.7 \mathrm{mph}$ and $10 \%$ respectively. The incline is incremented $2 \%$ every $3 \mathrm{~min}$ and the speed is incremented $0.8 \mathrm{mph}$ every $3 \mathrm{~min}$ until the treadmill reaches $22 \%$ grade and $6.0 \mathrm{mph}$. Respiration parameters were analyzed using Oxygen record (E. Jaeger, Würzburg, Germany). All exercise tests were terminated voluntarily by the subjects or when established criteria of test termination were met (Bruce et al. 1963). To be eligible to participate in the study, subjects had to be married men 25-40 years of age; in good health, as determined by a normal physical examination and routine laboratory tests within the previous year; with no history of chronic illness, serious systemic diseases, testicular varicocele and genital infection; with no history of use of antioxidants as supplements like vitamins and medications that could alter the hypothalamic-pituitary-gonadal (HPG) axis, such as anabolic steroids; with no history of use of cigarette and alcohol in the last 6 months; with regular eating patterns and with no history of depressive illness; with normal physical and sexual development; not working in professions where the activity might influence reproductive capacity; and with no relevant previous surgery (e.g., vasectomy reversal or varicocele removal). Individuals participating in a regular exercise program or accumulating 25 min or more of moderate physical activity on most days of the week or those unable to participate in the physical activity program were excluded (Tartibian \& Maleki 2012a,b, Tartibian et al. 2012, Hajizadeh Maleki et al. 2013, Maleki et al. 2014, 2016b, Hajizadeh Maleki \& Tartibian 2015). Once they met the inclusion criteria, eligible subjects $(n=280)$ provided written informed consent and entered the study and were randomly assigned to one of 4 groups: MICT $(n=70)$, HICT $(n=70)$, HIIT $(n=70)$ and non-exercise (NON-EX, $n=70$ ) groups (Table 1). With an $\alpha=0.05$, an effect size $=0.89$ and a power of 0.97 , a sample size of 70 was recommended. Randomization was performed by random number generation, and group assignment was placed in a sealed envelope, which was opened by the study 
Table 1 Demographic and physiological parameters at baseline.

\begin{tabular}{|c|c|c|c|c|c|}
\hline & MICT $(n=66)$ & HICT $(n=62)$ & HIIT $(n=65)$ & NON-EX $(n=68)$ & $P$ Values \\
\hline Age (year) & $31 \pm 8.7$ & $32.3 \pm 7.3$ & $30.4 \pm 8.9$ & $31.8 \pm 8.5$ & 0.091 \\
\hline Height $(\mathrm{cm})$ & $177 \pm 6.2$ & $175 \pm 5.9$ & $174 \pm 4.6$ & $176 \pm 8.1$ & 0.084 \\
\hline Weight (kg) & $82.2 \pm 6.8$ & $81.9 \pm 7.2$ & $83.4 \pm 6.3$ & $84.7 \pm 5.9$ & 0.096 \\
\hline $\mathrm{BMI}\left(\mathrm{kg} / \mathrm{m}^{2}\right)$ & $26.3 \pm 5.2$ & $26.8 \pm 5.9$ & $27.6 \pm 4.8$ & $27.4 \pm 6.1$ & 0.128 \\
\hline Fat $(\%)$ & $21.4 \pm 5.8$ & $21.9 \pm 6.3$ & $23.0 \pm 6.8$ & $22.8 \pm 6.2$ & 0.101 \\
\hline Waist circumference $(\mathrm{cm})$ & $120.2 \pm 14.7$ & $119.4 \pm 17.2$ & $123.1 \pm 22.1$ & $124.0 \pm 18.9$ & 0.091 \\
\hline $\mathrm{VO}_{2 \max }(\mathrm{mL} / \mathrm{kg} / \mathrm{min})$ & $35.5 \pm 4.2$ & $36.0 \pm 4.6$ & $35.9 \pm 4.7$ & $36.2 \pm 5.7$ & 0.073 \\
\hline
\end{tabular}

$* P<0.05$, significant difference between groups.

$\mathrm{HICT}$, high intensity continuous training; HIIT, high intensity interval training; MICT, moderate intensity continuous training;

NON-EX, non-exercise.

coordinator at the time of randomization. Nineteen subjects (MICT, $n=4$; HICT, $n=8$; HIIT, $n=5$; and NON-EX, $n=2$ ) could not complete the study protocol and were excluded from the study. Thus, 261 subjects remained in the analysis (Fig. 1). Subjects had anthropometric characteristics (weight, $\mathrm{BMI}$, body fat and waist circumference), aerobic capacity $\left(\mathrm{VO}_{2 \max }\right)$, inflammatory markers (IL- $\beta, \mathrm{IL}-6, \mathrm{IL}-8$ and TNF- $\alpha$ ), oxidants (ROS, malondialdehyde (MDA) and 8-isoprostane), antioxidants (superoxide dismutase (SOD), catalase and total antioxidant capacity (TAC)), semen parameters and sperm DNA damage measured at baseline $\left(T_{1}\right)$, the end of week 12 $\left(T_{2}\right)$, the end of week $24\left(T_{3}\right)$, and $7\left(T_{4}\right)$ and 30 days $\left(T_{5}\right)$ after training.

\section{MICT protocol}

During the first 12 weeks of moderate-intensity aerobic exercise, subjects walked or jogged on a treadmill 25-30 min/day,

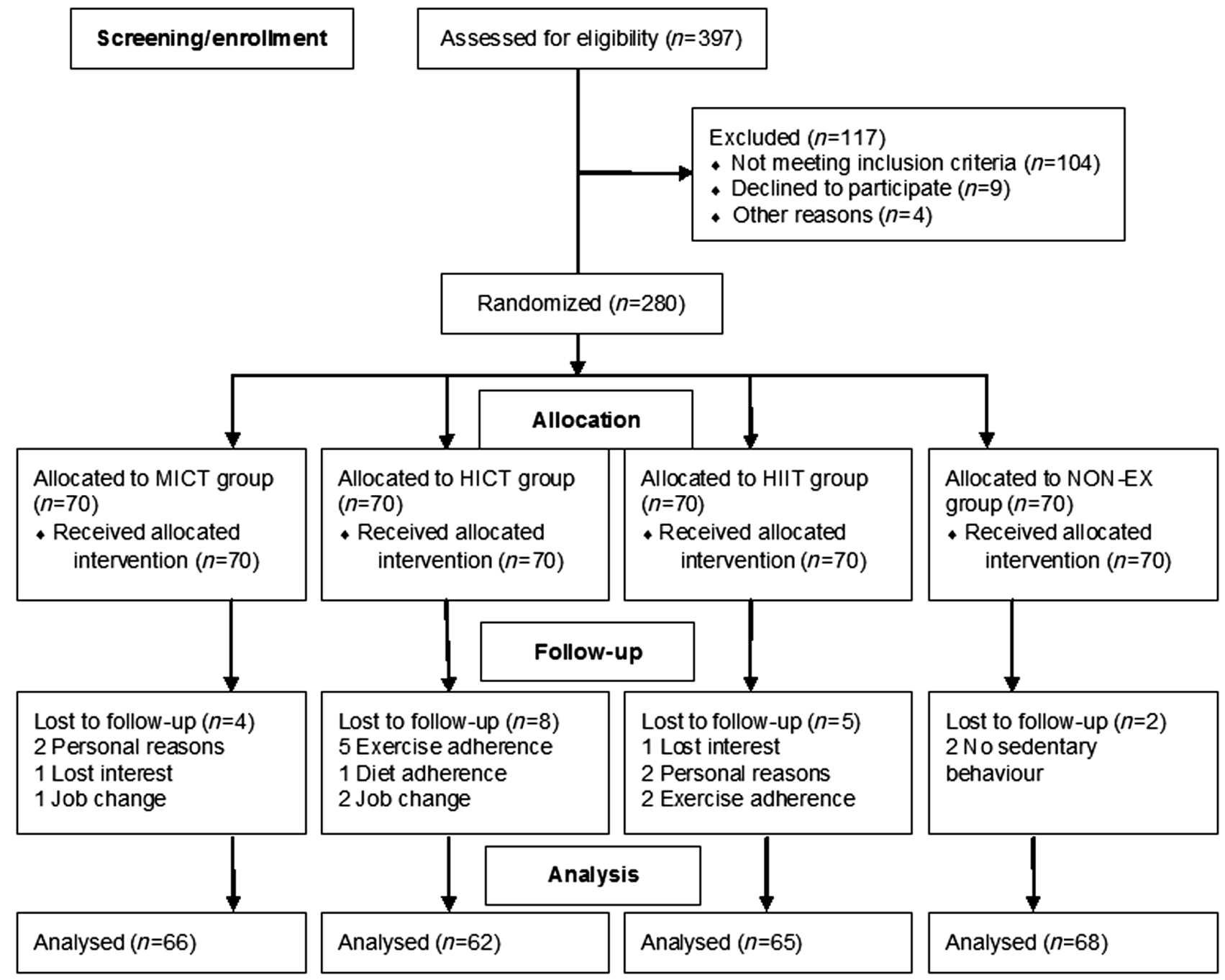

Figure 1 Follow-up diagram. 
3-4 days/week, at 45-55\% of their $\mathrm{VO}_{2 \max }$ and then increased to $40-45 \mathrm{~min} /$ day, $4-6$ days/week at an intensity of $56-69 \%$ of $\mathrm{VO}_{2 \max }$ during the final 12 weeks. All training sessions consisted of $10-15 \mathrm{~min}$ of warm-up $\left(40-45 \% \mathrm{VO}_{2 \max }\right)$ and cool-down $\left(35-40 \% \mathrm{VO}_{2 \max }\right)$.

\section{HICT protocol}

During the first 12 weeks of high-intensity exercise training, subjects performed a 40- to 50-min treadmill running protocol, 3 times a week, consisting of $10 \mathrm{~min}$ of running at $70-75 \%$ of their $\mathrm{VO}_{2 \max }$ (the work phase) followed by a $3 \mathrm{~min}$ at $50-60 \%$ of $\mathrm{VO}_{2 \max }$ (the recovery phase). This cycle was repeated four times within each exercise session. During the final 12 weeks, participants performed a 50- to 60-min treadmill running protocol, 3 times a week, consisting of $10 \mathrm{~min}$ of running at $75-85 \%$ of their $\mathrm{VO}_{2 \max }$ (the work phase) followed by $3 \mathrm{~min}$ at $50-60 \%$ of $\mathrm{VO}_{2 \max }$ (the recovery phase). This cycle was repeated five times within each exercise session. All training sessions consisted of $10-15$ min of warm-up (50-55\% VO $\left.{ }_{2 \max }\right)$ and cool-down $\left(40-45 \% \mathrm{VO}_{2 \max }\right)$.

\section{HIIT protocol}

Subjects participated in supervised HIIT on treadmill 3 times a week for 24 weeks. During the first 12 weeks of HIIT, subjects performed $10 \times 1$-min intervals $\left(75-85 \%\right.$ of $\left.\mathrm{VO}_{2 \max }\right)$ each interspersed by $1 \mathrm{~min}$ of recovery with $45-50 \%$ of $\mathrm{VO}_{2 \max }$. During the final 12 weeks, subjects performed $15 \times 1$-min intervals $\left(85-95 \%\right.$ of $\left.\mathrm{VO}_{2 \max }\right)$ followed by $1 \mathrm{~min}$ of recovery with $45-50 \%$ of $\mathrm{VO}_{2 \max }$ between each interval. In each training session, a warm-up of 10 - to $15-\min \left(50-55 \% \mathrm{VO}_{2 \max }\right.$ ) and a cool-down of $10-15 \mathrm{~min}\left(40-45 \% \mathrm{VO}_{2 \max }\right)$ were performed.

All training sessions were performed at the same time of the day (17:00-19:00 h) and instructions in correct exercise techniques and supervision of the participants throughout the entire training period were performed by a professional instructor and an experienced physician. Exercise adherence was documented through the use of Polar heart rate monitors, and subjects received feedback to adjust to the prescribed intensity. The NON-EX group subjects were instructed to maintain their current physical activity levels during the study as previously described. All subjects were requested to maintain their normal daily activities and not to modify their lifestyles during the 24-week intervention period other than to comply with the requirements of the study. Subjects were asked to refrain from exercising during the post-training period.

\section{Dietary and medication intake measures}

Trained dietitians collected dietary data over preceding 12 months using a validated semi-quantitative food frequency questionnaire (FFQ) (Tartibian \& Maleki 2012a,b, Tartibian et al. 2012, Hajizadeh Maleki et al. 2013, Maleki et al. 2014, 2016a,b, Hajizadeh Maleki \& Tartibian 2015). Subjects were required to maintain their normal diet during the period of study and instructed to consume a diet as similar as possible in each sampling days. A detailed diary of all types and household measures of food and drinks consumed, including brand names, was recorded at baseline and 30 days after training. Data from the diary were used to check compliance with the diet and ensure that dietary intake did not vary more than that would be expected over the study. Subjects were required to avoid any prescriptive or over-the-counter medications/ supplements and foods that may influence the reproductive function one week before and during the study. Information on use of medications/supplements was also obtained through standard and self-reported questionnaires.

\section{Anthropometric characteristics and aerobic capacity}

Height and body weight were measured to the nearest $0.25 \mathrm{~cm}$ and nearest $0.1 \mathrm{~kg}$ respectively, using a floor model physician's scale/stadiometer. Percent body fat and BMI were measured using a body fat analyzer (Omron HBF 306, Japan). Waist circumference also was measured with the standardized cloth tape measure. Additionally, $\mathrm{VO}_{2 \max }$ was measured using the Bruce protocol (Bruce et al. 1963).

\section{Measurements}

\section{Semen sampling and assays}

All the subjects were given clear instructions on how to collect their semen samples, and all the samples were provided on site. Each subject collected his semen sample by masturbation into a sterile container. All subjects were advised to observe an abstinence of 3 days and to deliver semen sample on the 4th day (Tartibian \& Maleki 2012a,b, Tartibian et al. 2012, Hajizadeh Maleki et al. 2013, Maleki et al. 2014, 2016b, Hajizadeh Maleki \& Tartibian 2015). Abstinence times did not differ between the groups. Samples were taken at baseline, 12 weeks, 24 weeks and 7 and 30 days after training. All samples were taken $24 \mathrm{~h}$ after the last exercise bout. After allowing at least $30 \mathrm{~min}$ for liquefaction to occur, semen analysis was performed to measure semen volume, progressive motility, sperm morphology, sperm concentration and number of spermatozoa according to World Health Organization (WHO) guidelines for the examination of human semen (WHO 2010). Liquefied semen samples were centrifuged at $10,000 \mathrm{~g}$ for $10 \mathrm{~min}$. The supernatant seminal plasma was then frozen at $-80^{\circ} \mathrm{C}$ until examination. Semen evaluations were performed on each sample by the same experienced technician throughout the study for the assessment of sperm DNA damage, seminal ROS, MDA, 8-isoprostane, SOD, catalase, TAC, IL- $\beta$, IL- 6 , IL-8 and TNF- $\alpha$.

\section{Sperm DNA fragmentation assay}

Sperm DNA fragmentation was evaluated with the terminal deoxynucleotidyl transferase-mediated fluorescein-dUTP nick end labeling (TUNEL) assay using Apo-Direct kit (Pharmingen, San Diego, CA, USA) as established earlier (Gorczyca et al. 1993, Mahfouz et al. 2009a). Briefly, 1-2 million spermatozoa were washed in phosphate-buffered saline (PBS), resuspended in $3.7 \%$ paraformaldehyde with adjustment of the concentration to $1-2 \times 10^{6} \mathrm{sperm} / \mathrm{mL}$ and placed on ice for $30-60 \mathrm{~min}$ at $4{ }^{\circ} \mathrm{C}$. Thereafter, spermatozoa were again washed to remove the paraformaldehyde and then resuspended in 
$70 \%$ ice-cold ethanol. Specimens were kept at $-20^{\circ} \mathrm{C}$ until the run time. In addition, we also included an internal set of samples that were tested negative or positive for DNA damage with each run. After a second wash in PBS to remove the ethanol, sperm pellets were resuspended in $50 \mu \mathrm{L}$ of the freshly prepared staining solution for $60 \mathrm{~min}$ at $37^{\circ} \mathrm{C}$. According to the manufacturer's instructions, the staining solution contains terminal deoxytransferase (TdT) enzyme, TdT reaction buffer, fluorescein isothiocyanate-tagged deoxyuridine triphosphate nucleotides (FITC-dUTP) and distilled water. All specimens were further washed in rinse buffer to remove the unbound reaction solution, resuspended in $0.5 \mathrm{~mL}$ of propidium iodide/ RNase solution and incubated for $30 \mathrm{~min}$ in the dark at room temperature. All fluorescence signals of labeled spermatozoa were analyzed by the flow cytometer FACScan (Becton Dickinson, San Jose, CA, USA). About 10,000 spermatozoa were examined for each assay at a flow rate of less than 100 cells/s. The excitation wavelength was $488 \mathrm{~nm}$ supplied by an argon laser at $15 \mathrm{~mW}$. Green fluorescence $(480-530 \mathrm{~nm})$ was measured in the FL-1 channel, and red fluorescence (580-630 nm) was measured in the FL-2 channel. Gating was done to exclude debris and aggregates using $90^{\circ}$ and forwardangle light scatter. Both percentage of positive cells and the mean fluorescence were calculated on a 1023-channel scale using the flow cytometer software Flowjo version 6.2.4 (FlowJo, LLC, Ashland, OR, USA). The percentage of positive cells (TUNEL ${ }^{+v e}$ ) was calculated on a 1023-channel scale using the flow cytometer software (Flowjo Mac version 8.2.4, Flowjo, LLC) (Mahfouz et al. 2009b).

\section{ROS assay}

Levels of ROS were measured by a chemiluminescence assay (Moein et al. 2007). Fresh semen specimens were centrifuged at $300 \mathrm{~g}$ for $7 \mathrm{~min}$, and seminal plasma was removed. The pellet was washed with phosphate buffer saline (PBS) and resuspended in the same media. Ten milliliter of luminal (5-amino-2,3 dihydro-1,4 phthalazinedione; Sigma Chemical) were used as a probe and were added to the aliquot. A negative control was prepared by adding $10 \mu \mathrm{L}$ of PBS. The ROS levels were assessed by measuring chemiluminescence activity with an Autolamat LB 935 Luminometer (Berthold technologies, Bad-wildbad, Germany) in the integrated mode for $15 \mathrm{~min}$. The results were expressed as RLU (relative light unit) per 20 million spermatozoa.

\section{Lipid peroxidation (LPO) assay}

The LPO in seminal plasma was estimated by determining the MDA levels. Briefly, to prevent the oxidation of polyunsaturated free fatty acids during the assay, $0.5 \mathrm{~mL}$ of seminal plasma was added to $0.5 \mathrm{~mL}$ of Tris-hydrogen chloride $(\mathrm{HCl}) 0.04 \mathrm{M}$ and acetonitrile containing $0.1 \%$ butylated hydroxytoluene (BHT). After derivatization with 2,4-dinitrophenylhydrazine according to the method of Shara and coworkers (1992) with minor modifications, the samples were immediately stirred and extracted with $5 \mathrm{~mL}$ of pentane; finally, the samples were dried using nitrogen and analyzed by high-performance liquid chromatography (HPLC). A calibration curve with concentrations of MDA ranging from 0.5 to $10 \mathrm{nmol} / \mathrm{mL}$ was used for the MDA quantifications. The MDA hydrazone was quantified by isocratic high-performance liquid chromatography using a Waters 600 E System Controller HPLC (Milford, MA, USA) equipped with a Waters Dual k 2487 UV detector (Milford, MA, USA) set at $307 \mathrm{~nm}$. A $5 \mathrm{~L}$ ultrasphere ODS column C18 (Beckman, San Ramon, CA, USA) was used to separate the hydrazone derivative at the flow rate of $0.8 \mathrm{~mL} / \mathrm{min}$ with the acetonitrile $(45 \%)-\mathrm{HCl} 0.01 \mathrm{M}(55 \%)$ as mobile phase. The MDA concentrations were calculated by peak areas determined using an Agilent 3395 integrator (Agilent Technologies) (Shara et al. 1992).

\section{8-Isoprostane assay}

We assessed free form of 8-Isoprostane and only the fraction shedded to seminal plasma from cell membranes.

\section{Free 8-isoprostane purification}

Free 8-isoprostane was purified by affinity chromatography method (Nonaka-Sarukawa et al. 2003). We used commercially available affinity column (Cayman Chemical, Ann Arbor, MI, USA). All samples were centrifuged at 15,000 g for isolation of particulates and precipitates. Then, the supernatant was diluted 1:5 with column buffer and applied to the column. Other procedures were conducted according to the instructions provided by the manufacturer. The ethanol washed 8 -Isoprostane was stored at $-80^{\circ} \mathrm{C}$ until measurement.

\section{Free 8-isoprostane}

At first, the elution solution was evaporated to dryness using a vacuum centrifugation. Then, the concentration of free 8-Isoprostane was measured by enzyme immunoassay (EIA) method (Nonaka-Sarukawa et al. 2003). We used commercially available EIA method (Cayman Chemical). The procedure for the EIA was followed according to the instructions provided by the manufacturer. The sample volume used was $50 \mu \mathrm{L}$. Absorbance was measured at a wavelength of $405 \mathrm{~nm}$ using enzyme-linked immunosorbent assay (ELISA) reader (STAT FAX 2100, St Louis, MO, USA). The levels of free 8-Isoprostane were presented as $\mathrm{ng} / \mathrm{mL}$. The intra-assay coefficient of variation was less than $10 \%$.

\section{TAC assay}

TAC was measured by colorimetric assay (Meucci et al. 2003, Said et al. 2003). We used commercially available colorimetric method (Randox Laboratories Ltd, UK). The frozen seminal plasma was thawed by placing the vials in a water bath at $37^{\circ} \mathrm{C}$ for $20 \mathrm{~min}$ and immediately assessed for its antioxidant capacity. Twenty microliters of seminal plasma were added to $1 \mathrm{~mL}$ of the reconstituted chromogen, 2,2'-azino-di-(3ethylbenzthiazoline sulphonate) (ABTS)-metmyoglobin $(10 \mathrm{~mL}$ vial with $10 \mathrm{~mL}$ of phosphate-buffered saline buffer). Twenty microliters of Trolox (6-hydroxyl-2,5,7,8-tetramethylchroman2-carboxylic acid) at a concentration of $1.71 \mathrm{mmol} / \mathrm{L}$ was used as the standard, whereas $20 \mu \mathrm{L}$ of deionized water was used as a blank. One milliliter of chromogen was added to the standard and blank samples. With spectrophotometer adjusted at a wavelength of $600 \mathrm{~nm}$, the initial absorbance (A1) was read. 
Two hundred microliters of $\mathrm{H}_{2} \mathrm{O}_{2}(250 \mu \mathrm{mol} / \mathrm{L})$ was then added to all tubes (standard, blank and sample), and absorbance (A2) was read exactly after $3 \mathrm{~min}$. The difference between A2 and $A 1(\triangle A)$ was calculated. The TAC of the sample was then calculated by the following formula:

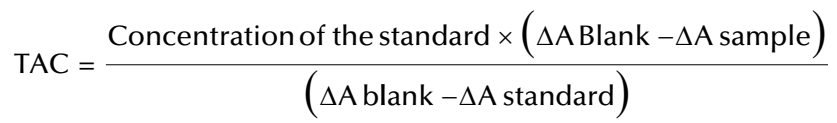

In this equation, $\mathrm{A} 1$ is the initial absorbance rate, $\mathrm{A} 2$ is the final absorbance rate and $\Delta \mathrm{A}$ is the difference between $\mathrm{A} 2$ and $\mathrm{A} 1$.

\section{SOD activity assay}

SOD activity was measured by colorimetric assay (Zini et al. 2002). We used commercially available colorimetric method (Randox Laboratories Ltd, Antrim, UK). This method employs xanthine and xanthine oxidase to generate superoxide radicals, which reacts with 2-(4-iodophenyl)-3-(4-nitrophenol)-5phenyltetrazoliumchloride (INT) to form red formazan dye. The SOD activity is then measured by the degree of inhibition of this reaction. One unit of SOD inhibits the reduction of INT by $50 \%$ under the conditions of the assay. After thawing, the seminal plasma was diluted 30 -fold with $10 \mathrm{mM}$ phosphate buffer, pH 7.0. Assay was performed at $37^{\circ} \mathrm{C}$. Phosphate buffer was used as blank. Mixed substrate and xanthine oxidase were added into standards and sample tubes and vortexed well. With spectrophotometer adjusted at a wavelength of $505 \mathrm{~nm}$, the initial absorbance (A1) was read. Final absorbance (A2) was read exactly after $3 \mathrm{~min}$. Percentages of inhibition of standards and samples were calculated. The SOD activity was measured using calibration curve of percentage inhibition for each standard against Log10 of standards, and SOD activity was expressed as $\mathrm{U} / \mathrm{mL}$.

\section{Catalase activity assay}

Catalase activity was estimated by the method of Aebi (Aebi 1984). Catalase can degrade hydrogen peroxide, which can be measured directly by the decrease in the absorbance at $240 \mathrm{~nm}$. The hydrogen peroxide was diluted with phosphate buffer $\mathrm{pH} 7.0$ and its initial absorbance was adjusted between 0.5 and 0.6 absorbance unit at $240 \mathrm{~nm}$. The decrease in the absorbance was measured. One unit of catalase activity was defined as the amount of catalase that was absorbed in $30 \mathrm{~s}$ at $25^{\circ} \mathrm{C}$. The catalase activity was then calculated from the change in absorbance and finally expressed as $\mathrm{U} / \mathrm{mL}$.

\section{Cytokines assay}

The Predicta (Cambridge, MA, USA) IL-1 $\beta$, IL-6, IL-8 and TNF$\alpha$ enzyme immunoassay kits contain a 96 -well microtiter plate precoated with monoclonal antibody to a proper cytokine. A measured volume of the studied samples, either standard substance or control buffer, was added to each test well and incubated to allow any cytokine present to be captured by antibodies on the microtiter plate. The wells were then washed, and a biotin-labeled polyclonal antibody to the tested cytokine was added to bind the captured IL-1 $\beta$, IL-6, IL-8 or TNF- $\alpha$. The wells were washed again and a peroxidase-labeled avidin reagent was added to attach the biotin (in the immune complex) on the plate. After incubation, the wells were washed and a peroxidase-labeled goat anti-rabbit immunoglobulin G was added to attach the polyclonal antibody (in the immune complex) on the plate. After a third wash, a substrate buffer (peroxide) and chromogen (tetramethylbenzidine) were added to the wells, thereby producing a blue color in the presence of peroxidase. The color reaction was stopped by the addition of sulfuric acid, which converted the blue color to yellow. The intensity of the colorimetric reactions was in a direct proportion to the amount of tested cytokine present in the studied sample or standard. The absorbance was read with Multiscan Plus (Labsystems, Helsinki, Finland) at $450 \mathrm{~nm}$, and a standard curve was constructed to quantitate cytokine concentrations. The results were expressed as pg/mL (Sanocka et al. 2003).

\section{Statistical analysis}

Group differences were determined using a one-way analysis of variance (ANOVA) for repeated measures, for continuous variables. If the main effects $F$ ratio was significant, differences among groups were subsequently identified using a Bonferroni post hoc analysis. Partial correlation and mixed model regression coefficients were used to evaluate the association between the variables studied. The statistical software program SPSS (SPSS, version 23) for windows was used for data analysis. All statistical tests were performed and considered significant at a $P \leq 0.05$.

\section{Results}

Baseline characteristics of the four study groups did not show any significant differences among groups in weight, $\mathrm{BMI}$, body fat, waist circumference, $\mathrm{VO}_{2 \max }$, semen volume, progressive motility, sperm morphology, sperm concentration, number of spermatozoa, percentage of TUNEL-positive spermatozoa, SOD, catalase, TAC, ROS, MDA, 8-isoprostane, IL-1 $\beta$, IL-6, IL-8 and TNF- $\alpha$ $(P>0.05)$.

\section{Dietary and medication intake}

Subjects' dietary intakes including the quality, quantity and frequency of consumption of foods including red meat, chicken, fish, eggs, vegetables, fruits and milky products were similar in all groups, and the dietary intakes between the groups or within the groups did not alter more than would be expected over the 24 weeks of the study $(P>0.05)$.

\section{Anthropometric characteristics and aerobic capacity}

In the MICT and HIIT groups, weight, body fat percent, waist circumference and $\mathrm{VO}_{2 \max }$ were significantly modulated by 12 and 24 weeks of exercise training compared to baseline $(P<0.05)$. BMI was significantly 

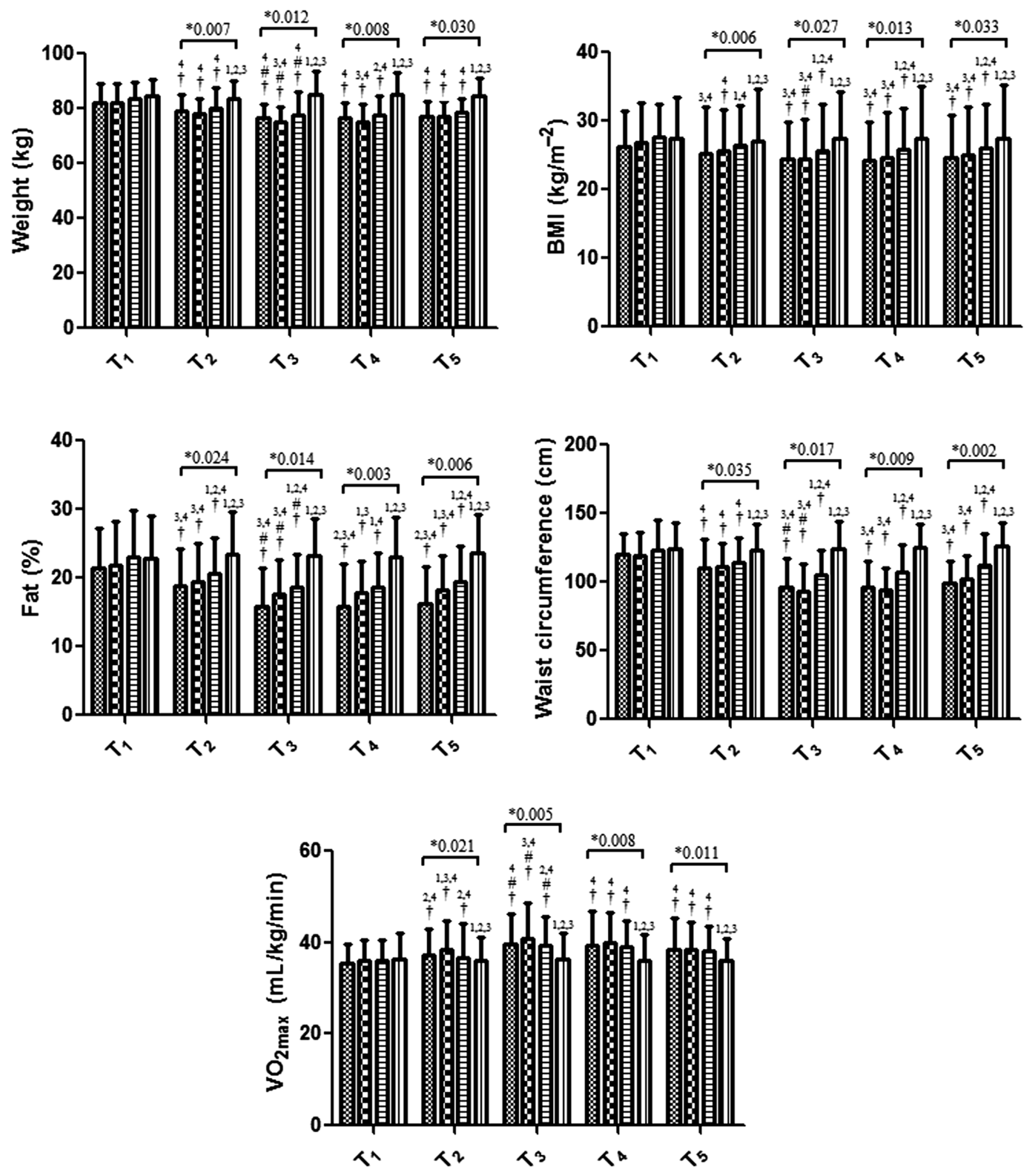

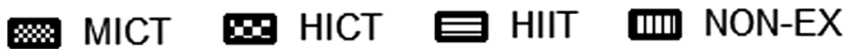

Figure 2 Baseline, week 12, week 24, and 7 and 30-day values of anthropometric characteristics and aerobic capacity in different groups of healthy male subjects. MICT, moderate-intensity continuous training; HICT, high intensity continuous training; HIIT, high-intensity interval training; NON-EX, non-exercise. $\mathrm{T}_{1}$ : baseline ( $24 \mathrm{~h}$ before training session). $\mathrm{T}_{2}: 24 \mathrm{~h}$ after the last training session in week $12 . \mathrm{T}_{3}: 24 \mathrm{~h}$ after the last training session in week 24. $\mathrm{T}_{4}: 7$ days after the last training session in week $24 . \mathrm{T}_{5}: 30$ days after the last training session in week 24. ${ }^{*} P<0.05$, significant difference between groups. ${ }^{\dagger} P<0.05$, significantly different from baseline values (within groups, baseline vs week 12 ). ${ }^{\sharp} P<0.05$, significantly different from week 12 values (within groups, week 12 vs week 24). Superscripts denote significant differences among the groups $(\mathrm{MICT}=1 ; \mathrm{HICT}=2 ; \mathrm{HIIT}=3$; and $\mathrm{NON}-\mathrm{EX}=4)$. 
altered after 24 weeks of training protocol compared to baseline in these groups $(P<0.05)$ (Fig. 2). In the HICT group, weight, $\mathrm{BMI}$, body fat percent, waist circumference and $\mathrm{VO}_{2 \max }$ were significantly modulated by 12 and 24 weeks of exercise training compared to baseline $(P<0.05)$. These changes remained significantly altered compared to baseline at 30 days after training in MICT, HICT and HIIT groups $(P<0.05)$ (Fig. 2). Significantly lower values were observed for weight, BMI, body fat percent and waist circumference in the MICT, HICT and HIIT groups compared with the NON-EX group $(P<0.05)$. Further, there were significantly enhanced values for $\mathrm{VO}_{2 \max }$ in the MICT, HICT and HIIT groups compared with the NON-EX group $(P<0.05)$. At 24 weeks, the HICT changes of body weight were significantly greater than those in the HIIT group $(P<0.05)$. At 12 weeks, changes in BMI were significantly greater in the HICT group than those found in the HIIT group $(P<0.05)$. By 24 weeks, MICT and HICT interventions resulted in greater changes in $\mathrm{BMI}$ than those seen in the HIIT and NON-EX groups $(P<0.05)$. The MICT and HICT values of body fat percent were significantly lower than those in the HIIT and NON-EX groups $(P<0.05)$. At 12 and 24 weeks, the MICT and HICT changes of waist circumference were significantly greater than those of the HIIT group $(P<0.05)$. At 12 weeks, the HICT changes of $\mathrm{VO}_{2 \max }$ were significantly greater than the other groups $(P<0.05)$. Likewise, at 24 weeks, the HICT changes of $\mathrm{VO}_{2 \max }$ were significantly greater than the HIIT group $(P<0.05)$. The NON-EX group demonstrated no significant changes in these parameters in the 24 weeks $(P>0.05)$ (Fig. 2).

\section{Semen parameters}

In the MICT group, progressive motility, sperm morphology and sperm concentration were significantly modulated by 12 and 24 weeks of exercise training compared to baseline $(P<0.05)$. Semen volume and number of spermatozoa were significantly altered after 24 weeks of training protocol compared to baseline $(P<0.05)$. These alterations were maintained 7 days after training. Only semen volume and progressive motility remained significantly altered compared to baseline at 30 days after training $(P<0.05)$ (Fig. 3). In the HICT group, sperm concentration was significantly modulated by 12 and 24 weeks of exercise training compared to baseline $(P<0.05)$. Progressive motility and sperm morphology were significantly altered after 24 weeks of training protocol compared to baseline $(P<0.05)$. Alterations in progressive motility and sperm concentration were maintained 7 days after training (Fig. 3). In the HIIT group, sperm morphology and sperm concentration were significantly modulated by 12 and 24 weeks of exercise training compared to baseline $(P<0.05)$. Progressive motility was significantly altered after 24 weeks of training protocol compared to baseline $(P<0.05)$. Alterations in progressive motility and sperm concentration were maintained 7 days after training (Fig. 3). At 12 weeks, the MICT changes of progressive motility were significantly greater than those of the HIIT and NON-EX groups, whereas at 24 weeks, these changes were greater in the MICT than observed in any of the other groups $(P<0.05)$. By 12 weeks, the MICT changes of sperm morphology were significantly greater than the HICT and NON-EX groups, whereas at 24 weeks, these changes were greater in the MICT than those observed in any of the other groups $(P<0.05)$. Also, at 12 and 24 weeks, the MICT changes of sperm concentration were significantly greater than those observed in any of the other groups $(P<0.05)$. Further, at 24 weeks, the MICT changes of number of spermatozoa were significantly greater than those observed in any of the other groups $(P<0.05)$. The NON-EX group demonstrated no significant changes in semen quality parameters in the 24 weeks $(P>0.05)$ (Fig. 3$)$.

\section{Sperm DNA fragmentation}

In the MICT, HICT and HIIT groups, percentage of TUNEL-positive spermatozoa were significantly modulated by 24 weeks of exercise training compared to baseline $(P<0.05)$. These alterations were maintained 7 days after training in the MICT group $(P<0.05)$ (Fig. 3). Significantly lower values were observed for percentage of TUNEL-positive spermatozoa in the MICT, HICT and HIIT groups compared with the NON-EX group $(P<0.05)$. The NON-EX group demonstrated no significant changes in percentage of TUNEL-positive spermatozoa in the 24 weeks $(P>0.05)$ (Fig. 3$)$.

\section{Oxidants and antioxidants}

In the MICT group, ROS, MDA and catalase were significantly modulated by 12 and 24 weeks of exercise training compared to baseline $(P<0.05)$. SOD, TAC and 8 -isoprostane were significantly altered after 24 weeks of training protocol compared to baseline $(P<0.05)$. These alterations were maintained 7 days after training. Only catalase and ROS remained significantly altered compared to baseline at 30 days after training $(P<0.05)$ (Table 2). In the HICT group, ROS, SOD and catalase were significantly attenuated by 24 weeks of exercise training compared to baseline $(P<0.05)$. SOD and catalase alterations were maintained 7 days after training (Table 2). In the HIIT group, ROS, MDA, SOD, catalase and TAC were significantly attenuated by 24 weeks of exercise training compared to baseline $(P<0.05)$. TAC and ROS alterations were maintained 7 days after training. Only catalase remained significantly altered compared to baseline at 30 days after training in this group $(P<0.05)$ (Table 2$)$. Significantly lower values were observed for ROS, MDA and 8-isoprostane in the MICT, HICT and HIIT groups compared with 

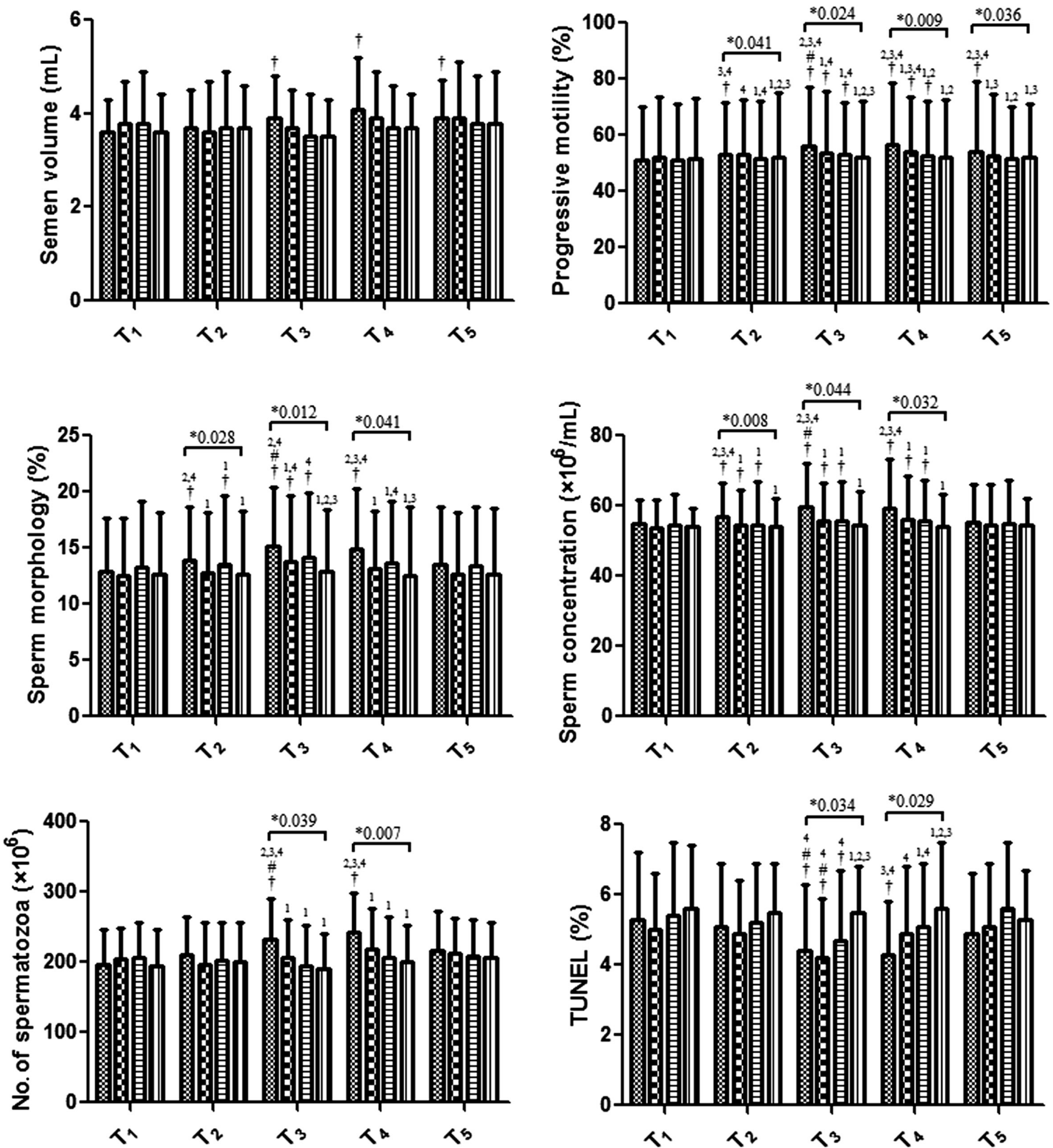

MICT $\mathbf{m}$ HICT $\quad$ H HIT 血 NON-EX

Figure 3 Baseline, week 12, week 24, and 7 and 30-day values of semen quality parameters and sperm DNA integrity in different groups of healthy male subjects. MICT, moderate-intensity continuous training; HICT, high-intensity continuous training; HIIT, high-intensity interval training; NON-EX, non-exercise. $\mathrm{T}_{1}$ : baseline ( $24 \mathrm{~h}$ before training session). $\mathrm{T}_{2}: 24 \mathrm{~h}$ after the last training session in week $12 . \mathrm{T}_{3}: 24 \mathrm{~h}$ after the last training session in week 24. $\mathrm{T}_{4}: 7$ days after the last training session in week $24 . \mathrm{T}_{5}: 30$ days after the last training session in week 24. ${ }^{*} P<0.05$, significant difference between groups. ${ }^{\dagger} P<0.05$, significantly different from baseline values (within groups, baseline vs week 12 ). ${ }^{\sharp} P<0.05$, significantly different from week 12 values (within groups, week 12 vs week 24). Superscripts denote significant differences among the groups $(\mathrm{MICT}=1 ; \mathrm{HICT}=2 ; \mathrm{HIIT}=3$; and $\mathrm{NON}-\mathrm{EX}=4)$. 
Table 2 Baseline, week 12, week 24, and 7 and 30 days values of seminal oxidants and antioxidants in different groups of healthy male subjects.

\begin{tabular}{|c|c|c|c|c|c|}
\hline & MICT $(n=66)$ & HICT $(n=62)$ & HIIT $(n=65)$ & NON-EX $(n=68)$ & $P$ Values \\
\hline \multicolumn{6}{|c|}{$\mathrm{SOD}(\mathrm{U} / \mathrm{mL})$} \\
\hline $\mathrm{T}_{1}$ & $5.1 \pm 0.9$ & $5.4 \pm 1.1$ & $5.5 \pm 0.9$ & $5.2 \pm 1.0$ & 0.085 \\
\hline $\mathrm{T}_{2}$ & $5.2 \pm 1.4$ & $5.3 \pm 1.2$ & $5.7 \pm 1.1$ & $5.1 \pm 1.2$ & 0.067 \\
\hline $\mathrm{T}_{3}^{2}$ & $6.1 \pm 1.2^{4, \#,+}$ & $6.0 \pm 1.4^{4, t}$ & $6.3 \pm 1.4^{4, t}$ & $5.3 \pm 1.1^{1,2,3}$ & $* 0.039$ \\
\hline $\mathrm{T}_{4}$ & $6.3 \pm 1.3^{4,+}$ & $5.7 \pm 1.5$ & $5.9 \pm 1.1$ & $5.2 \pm 1.4^{1}$ & $* 0.024$ \\
\hline $\mathrm{T}_{5}^{4}$ & $5.3 \pm 1.4$ & $5.5 \pm 1.2$ & $5.6 \pm 1.6$ & $5.1 \pm 1.1$ & 0.091 \\
\hline \multicolumn{6}{|c|}{ Catalase $(\mathrm{U} / \mathrm{mL})$} \\
\hline $\mathrm{T}_{1}$ & $20.9 \pm 7.8$ & $22.7 \pm 8.1$ & $21.8 \pm 9.5$ & $22.2 \pm 8.9$ & 0.127 \\
\hline $\mathrm{T}_{2}$ & $24.0 \pm 8.1^{3,4,+}$ & $22.9 \pm 9.6$ & $22.0 \pm 8.7^{1}$ & $22.4 \pm 9.3^{1}$ & $* 0.041$ \\
\hline $\mathrm{T}_{3}^{2}$ & $28.3 \pm 10.4^{2,3,4, \#,+}$ & $25.1 \pm 9.7^{1,4, \#,+}$ & $24.9 \pm 11.1^{1,4, \#,+}$ & $22.0 \pm 9.6^{1,2,3}$ & $* 0.016$ \\
\hline $\mathrm{T}_{4}$ & $27.9 \pm 9.1^{2,3,4,+}$ & $24.9 \pm 9.4^{1,4,+}$ & $25.1 \pm 9.7^{1,4,+}$ & $22.3 \pm 8.8^{1,2,3}$ & $* 0.005$ \\
\hline $\mathrm{T}_{5}^{4}$ & $24.6 \pm 10.8^{2,3,4,+}$ & $23.2 \pm 10.8^{1,4}$ & $23.5 \pm 11.2^{1,4,+}$ & $22.5 \pm 8.4^{1,2,3}$ & $* 0.017$ \\
\hline \multicolumn{6}{|c|}{ TAC (mM) } \\
\hline $\mathrm{T}_{1}$ & $1.3 \pm 0.7$ & $1.1 \pm 0.5$ & $1.1 \pm 0.7$ & $1.2 \pm 0.5$ & 0.065 \\
\hline $\mathrm{T}_{2}$ & $1.4 \pm 0.9$ & $1.2 \pm 0.9$ & $1.2 \pm 0.8$ & $1.0 \pm 0.7$ & 0.059 \\
\hline $\mathrm{T}_{3}^{2}$ & $1.9 \pm 0.9^{2,4, \sharp, \dagger}$ & $1.2 \pm 0.8^{1}$ & $1.6 \pm 0.9^{+}$ & $1.3 \pm 0.8^{1}$ & $* 0.041$ \\
\hline $\mathrm{T}_{4}^{3}$ & $1.8 \pm 0.8^{2,4,+}$ & $1.3 \pm 0.9^{1}$ & $1.7 \pm 0.8^{+}$ & $1.2 \pm 0.9^{1}$ & $* 0.038$ \\
\hline $\mathrm{T}_{5}^{4}$ & $1.5 \pm 0.8$ & $1.2 \pm 0.8$ & $1.3 \pm 0.9$ & $1.1 \pm 0.9$ & 0.071 \\
\hline \multicolumn{6}{|c|}{ ROS (RLU) } \\
\hline $\mathrm{T}_{1}$ & $445.8 \pm 294$ & $431.6 \pm 198$ & $416.4 \pm 224$ & $424 \pm 212$ & 0.081 \\
\hline $\mathrm{T}_{2}$ & $397.9 \pm 214^{\dagger}$ & $417.9 \pm 214$ & $395.5 \pm 178$ & $409 \pm 198$ & 0.128 \\
\hline $\mathrm{T}_{3}^{2}$ & $312.9 \pm 224^{2,4, \sharp,+}$ & $376.9 \pm 176^{1,4, \sharp,+}$ & $347.8 \pm 195^{4, \#,+}$ & $435 \pm 229^{1,2,3}$ & $* 0.007$ \\
\hline $\mathrm{T}_{4}^{3}$ & $291 \pm 239^{2,3,4,+}$ & $367 \pm 193^{1,4,+}$ & $331 \pm 181^{1,4,+}$ & $414 \pm 174^{1,2,3}$ & $* 0.001$ \\
\hline $\mathrm{T}_{5}^{4}$ & $349 \pm 241^{2,3,4,+}$ & $419 \pm 208^{1}$ & $398 \pm 203^{1,4}$ & $444 \pm 231^{1,2,3}$ & $* 0.002$ \\
\hline \multicolumn{6}{|c|}{$\mathrm{MDA}(\mathrm{nmol} / \mathrm{mL})$} \\
\hline $\mathrm{T}_{1}$ & $0.38 \pm 0.19$ & $0.44 \pm 0.22$ & $0.41 \pm 0.15$ & $0.45 \pm 0.14$ & 0.093 \\
\hline $\mathrm{T}_{2}$ & $0.31 \pm 0.12^{2,4,+}$ & $0.41 \pm 0.19^{1}$ & $0.37 \pm 0.18$ & $0.42 \pm 0.17^{1}$ & $* 0.044$ \\
\hline $\mathrm{T}_{3}$ & $0.22 \pm 0.13^{2,3,4, \#,+}$ & $0.38 \pm 0.17^{4}$ & $0.31 \pm 0.15^{4,+}$ & $0.47 \pm 0.19^{1,2,3}$ & $* 0.006$ \\
\hline $\mathrm{T}_{4}$ & $0.23 \pm 0.14^{2,3,4,+}$ & $0.39 \pm 0.18^{1}$ & $0.36 \pm 0.19^{1}$ & $0.43 \pm 0.16^{1}$ & $* 0.002$ \\
\hline $\mathrm{T}_{5}^{4}$ & $0.33 \pm 0.17^{2,4}$ & $0.42 \pm 0.19^{1}$ & $0.39 \pm 0.19$ & $0.45 \pm 0.18^{1}$ & $* 0.023$ \\
\hline \multicolumn{6}{|c|}{ 8-Isoprostane $(\mathrm{ng} / \mathrm{mL})$} \\
\hline $\mathrm{T}_{1}$ & $7.3 \pm 2.1$ & $7.0 \pm 2.5$ & $7.4 \pm 2.8$ & $6.9 \pm 2.2$ & 0.241 \\
\hline $\mathrm{T}_{2}$ & $6.9 \pm 2.4$ & $6.8 \pm 2.9$ & $7.2 \pm 2.6$ & $7.1 \pm 2.5$ & 0.082 \\
\hline $\mathrm{T}_{3}^{2}$ & $6.1 \pm 2.2^{3,4,+}$ & $6.6 \pm 2.4$ & $7.0 \pm 2.3^{1}$ & $7.0 \pm 2.3^{1}$ & $* 0.019$ \\
\hline $\mathrm{T}_{4}$ & $6.2 \pm 2.4^{2,3,4,+}$ & $6.9 \pm 2.7^{1}$ & $7.1 \pm 2.7^{1}$ & $6.9 \pm 2.6^{1}$ & $* 0.044$ \\
\hline $\mathrm{T}_{5}^{4}$ & $6.7 \pm 2.3$ & $6.8 \pm 2.6$ & $7.3 \pm 2.4$ & $7.1 \pm 2.1$ & 0.069 \\
\hline
\end{tabular}

$\mathrm{T}_{1}$ : baseline ( $24 \mathrm{~h}$ before training session). $\mathrm{T}_{2}: 24 \mathrm{~h}$ after the last training session in week $12 . \mathrm{T}_{3}: 24 \mathrm{~h}$ after the last training session in week 24 . $\mathrm{T}_{4}: 7$ days after the last training session in week $24 . \mathrm{T}_{5}: 30$ days after the last training session in week 24.

$* P<0.05$, significant difference between groups. ${ }^{\dagger} P<0.05$, significantly different from baseline values (within groups, baseline vs week 12 ). ${ }^{\#} P<0.05$, significantly different from week 12 values (within groups, week 12 vs week 24). Superscripts denote significant differences among the groups (MICT $=1 ; \mathrm{HICT}=2 ; \mathrm{HIIT}=3$; and $\mathrm{NON}-\mathrm{EX}=4$ ).

$\mathrm{HICT}$, high intensity continuous training; HIIT, high intensity interval training; MICT, moderate intensity continuous training;

NON-EX, non-exercise.

the NON-EX group $(P<0.05)$. Further, there were significantly enhanced values for SOD, catalase and TAC in the MICT, HICT and HIIT groups compared with the NON-EX group $(P<0.05)$. At 24 weeks, the MICT changes of ROS were significantly greater than those observed in the HICT and NON-EX groups $(P<0.05)$. The MICT concentrations of 8-isoprostane were significantly lower than the HIIT and NON-EX groups $(P<0.05)$. At 12 weeks, the MICT changes of MDA were significantly greater than those of the HICT and NON-EX groups, whereas at 24 weeks, these changes were greater in the MICT than that observed in any of the other groups $(P<0.05)$. By 24 weeks, the MICT, HICT and HIIT changes of SOD were significantly greater than those observed in the NON-EX group $(P<0.05)$. At 12 and 24 weeks, the MICT changes of catalase were significantly greater than those observed in the HIIT and NON-EX group $(P<0.05)$. Likewise, at 12 and
24 weeks, the MICT changes of TAC were significantly greater than those observed in the HICT and NON-EX group $(P<0.05)$. The NON-EX group demonstrated no significant changes in seminal markers of oxidative stress in the 24 weeks $(P>0.05)$ (Table 2).

\section{Cytokines}

In the MICT group, IL-1 $\beta$, IL-6, IL- 8 and TNF- $\alpha$ were significantly modulated by 12 and 24 weeks of exercise training compared to baseline $(P<0.05)$. These changes remained significantly altered compared to baseline at 30 days after training $(P<0.05)$ (Table 3$)$. In the HICT group, IL-6 and TNF- $\alpha$ were significantly attenuated by 24 weeks of exercise training compared to baseline $(P<0.05)$. These alterations were maintained 7 days after training (Table 3 ). In the HIIT group, IL-1 $\beta$, IL-6, IL-8 and TNF- $\alpha$ were significantly altered by 24 weeks of exercise 
Table 3 Baseline, week 12, week 24, and 7 and 30 days values of seminal cytokines different groups of healthy male subjects.

\begin{tabular}{|c|c|c|c|c|c|}
\hline & MICT $(n=66)$ & HICT $(n=62)$ & HIIT $(n=65)$ & NON-EX $(n=68)$ & $P$ values \\
\hline \multicolumn{6}{|c|}{ IL-1 $\beta(p g / m L)$} \\
\hline $\mathrm{T}_{1}$ & $7.6 \pm 2.4$ & $7.3 \pm 2.7$ & $7.8 \pm 2.6$ & $7.7 \pm 2.8$ & 0.074 \\
\hline $\mathrm{T}_{2}$ & $6.3 \pm 2.1^{2,3,4,+}$ & $7.1 \pm 2.5^{1,4}$ & $7.4 \pm 2.9^{1}$ & $7.8 \pm 2.2^{1,2}$ & $* 0.035$ \\
\hline $\mathrm{T}_{3}$ & $5.0 \pm 2.0^{2,3,4, \sharp,+}$ & $6.9 \pm 2.6^{1}$ & $6.6 \pm 2.5^{1,4,+}$ & $7.4 \pm 2.5^{1,3}$ & $* 0.047$ \\
\hline $\mathrm{T}_{4}$ & $5.2 \pm 2.0^{2,3,4,+}$ & $7.1 \pm 2.2^{1}$ & $6.5 \pm 2.2^{1,4,+}$ & $7.7 \pm 2.4^{1,3}$ & $* 0.036$ \\
\hline $\mathrm{T}_{5}^{4}$ & $6.5 \pm 2.3^{3,4,+}$ & $7.0 \pm 2.4$ & $7.4 \pm 2.6^{1}$ & $7.6 \pm 2.6^{1}$ & $* 0.027$ \\
\hline \multicolumn{6}{|c|}{ IL-6 (pg/mL) } \\
\hline $\mathrm{T}_{1}$ & $16.5 \pm 5.1$ & $17.1 \pm 5.7$ & $16.8 \pm 6.3$ & $17.3 \pm 6.8$ & 0.069 \\
\hline $\mathrm{T}_{2}$ & $13.4 \pm 5.2^{2,3,4,+}$ & $16.7 \pm 5.9^{1}$ & $16.4 \pm 5.9^{1,4}$ & $17.4 \pm 6.2^{1,3}$ & $* 0.029$ \\
\hline $\mathrm{T}_{3}^{2}$ & $10.3 \pm 5.5^{2,3,4, \sharp,+}$ & $15.1 \pm 6.3^{1,4, \sharp,+}$ & $14.6 \pm 6.7^{1,4, \sharp,+}$ & $17.7 \pm 5.3^{1,2,3}$ & $* 0.003$ \\
\hline $\mathrm{T}_{4}$ & $10.4 \pm 6.3^{2,3,4,+}$ & $14.9 \pm 6.5^{1,4, \dagger}$ & $14.5 \pm 6.1^{1,4,+}$ & $17.1 \pm 6.3^{1,2,3}$ & $* 0.001$ \\
\hline \multirow{2}{*}{\multicolumn{6}{|c|}{ IL-8 (pg/mL) }} \\
\hline & & & & & \\
\hline $\mathrm{T}_{1}$ & $619 \pm 202$ & $638 \pm 232$ & $629 \pm 247$ & $607 \pm 221$ & 0.125 \\
\hline $\mathrm{T}_{2}$ & $554 \pm 185^{2,3,4,+}$ & $623 \pm 197^{1}$ & $604 \pm 219^{1}$ & $621 \pm 239^{1}$ & $* 0.022$ \\
\hline $\mathrm{T}_{3}^{2}$ & $511 \pm 198^{2,3,4, \#,+}$ & $612 \pm 215^{1,3}$ & $561 \pm 246^{1,2,4, \#,+}$ & $635 \pm 263^{1,3}$ & $* 0.004$ \\
\hline $\mathrm{T}_{4}$ & $520 \pm 212^{2,4,+}$ & $630 \pm 237^{1,3}$ & $548 \pm 227^{2,4,+}$ & $615 \pm 231^{1,3}$ & $* 0.007$ \\
\hline $\mathrm{T}_{5}^{4}$ & $543 \pm 236^{2,3,4,+}$ & $624 \pm 251^{1}$ & $611 \pm 242^{1}$ & $627 \pm 249^{1}$ & $* 0.002$ \\
\hline \multicolumn{6}{|c|}{ TNF- $\alpha(p g / m L)$} \\
\hline $\mathrm{T}_{1}$ & $6.2 \pm 1.8$ & $5.8 \pm 1.9$ & $6.3 \pm 2.4$ & $6.0 \pm 2.4$ & 0.087 \\
\hline $\mathrm{T}_{2}$ & $5.2 \pm 2.1^{3,4,+}$ & $5.5 \pm 2.3^{4}$ & $6.0 \pm 2.3^{1}$ & $6.2 \pm 2.0^{1}$ & $* 0.026$ \\
\hline $\mathrm{T}_{3}^{2}$ & $4.7 \pm 1.9^{4,+}$ & $4.7 \pm 1.6^{4,+}$ & $5.3 \pm 1.7^{4,+}$ & $6.1 \pm 2.7^{1,2,3}$ & $* 0.017$ \\
\hline $\mathrm{T}_{4}$ & $4.8 \pm 2.3^{4, t}$ & $4.6 \pm 2.2^{4,+}$ & $5.4 \pm 1.9^{+}$ & $5.8 \pm 2.4^{1,2}$ & $* 0.033$ \\
\hline $\mathrm{T}_{5}^{4}$ & $5.1 \pm 2.0^{3,4,+}$ & $5.3 \pm 2.4^{4}$ & $5.9 \pm 2.2^{1}$ & $6.2 \pm 2.5^{1,2}$ & $* 0.009$ \\
\hline
\end{tabular}

$\mathrm{T}_{1}$ : baseline ( $24 \mathrm{~h}$ before training session). $\mathrm{T}_{2}: 24 \mathrm{~h}$ after the last training session in week $12 . \mathrm{T}_{3}: 24 \mathrm{~h}$ after the last training session in week 24 . $\mathrm{T}_{4}: 7$ days after the last training session in week $24 . \mathrm{T}_{5}: 30$ days after the last training session in week 24.

${ }^{*} P<0.05$, significant difference between groups. ${ }^{+} P<0.05$, significantly different from baseline values (within groups, baseline vs week 12 ).

${ }^{\sharp} P<0.05$, significantly different from week 12 values (within groups, week 12 vs week 24 ). Superscripts denote significant differences among the groups (MICT $=1 ; \mathrm{HICT}=2 ; \mathrm{HIIT}=3$; and $\mathrm{NON}-\mathrm{EX}=4$ ).

HICT, high intensity continuous training; HIIT, high intensity interval training; MICT, moderate intensity continuous training;

NON-EX, non-exercise.

training compared to baseline. These alterations were maintained 7 days after training $(P<0.05)$ (Table 3$)$. Significantly lower values were observed for IL-1 $\beta$, IL-6, IL-8 and TNF- $\alpha$ in the MICT, HICT and HIIT groups compared with the NON-EX group $(P<0.05)$. At 12 and 24 weeks, the MICT changes of IL-1 $\beta$, IL-6 and IL-8 were significantly greater than those observed in any of the other groups $(P<0.05)$. The MICT concentrations of TNF- $\alpha$ were significantly lower than those in the HIIT and NON-EX groups $(P<0.05)$. The NON-EX group demonstrated no significant changes in seminal proinflammatory cytokines in the 24 weeks $(P>0.05)$ (Table 3).

\section{Correlations}

The association among body composition, maximal oxygen consumption, oxidants, antioxidants and cytokines with semen parameters and sperm DNA damage in all groups are shown in Table 4. Significant negative correlations were observed among progressive motility, sperm morphology, sperm concentration, number of spermatozoa and percentage of TUNELpositive spermatozoa with weight, BMI, body fat, waist circumference, ROS, MDA, 8-isoprostane, IL-1 $\beta$, IL-6, IL-8 and TNF- $\alpha$ (Table 4). Results from the mixed model regression revealed that each unit $(\%)$ increase in progressive motility was associated with a $4.3 \mathrm{~kg}$ reduction in weight, a $1.6 \mathrm{~kg} / \mathrm{m}^{2}$ reduction in $\mathrm{BMI}$, a $3.4 \%$ reduction in body fat, a $5.3 \mathrm{~cm}$ reduction in waist circumference, a $3.1 \mathrm{RLU}$ reduction in ROS, a $2.2 \mathrm{nmol} / \mathrm{mL}$ reduction in MDA, a $0.9 \mathrm{ng} / \mathrm{mL}$ reduction in 8 -isoprostane, a $4.9 \mathrm{pg} / \mathrm{mL}$ reduction in $\mathrm{IL}-1 \beta$, a $2.6 \mathrm{pg} / \mathrm{mL}$ reduction in $\mathrm{IL}-6$, a $2.7 \mathrm{pg} / \mathrm{mL}$ reduction in IL-8 and finally a $4.6 \mathrm{pg} / \mathrm{mL}$ reduction in TNF- $\alpha$. Furthermore, each unit (\%) increase in sperm morphology was associated with a $4.1 \mathrm{~kg}$ reduction in weight, a $1.7 \mathrm{~kg} / \mathrm{m}^{2}$ reduction in $\mathrm{BMI}$, a $2.1 \%$ reduction in body fat, a $6.3 \mathrm{~cm}$ reduction in waist circumference, a $3.3 \mathrm{RLU}$ reduction in $\mathrm{ROS}$, a $1.2 \mathrm{nmol} / \mathrm{mL}$ reduction in $\mathrm{MDA}$, a $1.7 \mathrm{ng} / \mathrm{mL}$ reduction in 8 -isoprostane, a $5.1 \mathrm{pg} / \mathrm{mL}$ reduction in $\mathrm{IL}-1 \beta$, a $2.2 \mathrm{pg} / \mathrm{mL}$ reduction in IL-6, a $3.4 \mathrm{pg} / \mathrm{mL}$ reduction in IL-8 and finally a $5.8 \mathrm{pg} / \mathrm{mL}$ reduction in TNF- $\alpha$. Likewise, each unit $\left(10^{6}\right)$ increase in number of spermatozoa was associated with a $3.1 \mathrm{~kg}$ reduction in weight, a $0.8 \mathrm{~kg} / \mathrm{m}^{2}$ reduction in $\mathrm{BMI}$, a $0.8 \%$ reduction in body fat, a $3.3 \mathrm{~cm}$ reduction in waist circumference, a $1.8 \mathrm{RLU}$ reduction in $\mathrm{ROS}$, a $0.9 \mathrm{nmol} / \mathrm{mL}$ reduction in $\mathrm{MDA}$, a $0.8 \mathrm{ng} / \mathrm{mL}$ reduction in 8 -isoprostane, a $3.3 \mathrm{pg} / \mathrm{mL}$ reduction in $\mathrm{IL}-1 \beta$, a $1.1 \mathrm{pg} / \mathrm{mL}$ reduction in $\mathrm{IL}-6$, a $1.8 \mathrm{pg} / \mathrm{mL}$ reduction in $\mathrm{IL}-8$ and finally a $2.1 \mathrm{pg} / \mathrm{mL}$ reduction in TNF- $\alpha$. Additionally, each unit (\%) improvement in TUNEL-positive spermatozoa was associated with a $4.0 \mathrm{~kg}$ reduction in weight, a $1.9 \mathrm{~kg} / \mathrm{m}^{2}$ reduction in $\mathrm{BMI}$, a $1.0 \%$ reduction in body fat, 
Table 4 Correlation of body composition measures, $\mathrm{VO}_{2 \max }$ antioxidants, oxidants and cytokines with semen quality parameters and sperm DNA integrity in healthy male subjects.

\begin{tabular}{|c|c|c|c|c|c|}
\hline & Progressive motility (\%) & Sperm morphology $(\%)$ & $\begin{array}{c}\text { Sperm concentration } \\
\left(\times 10^{6} / \mathrm{mL}\right)\end{array}$ & $\begin{array}{c}\text { No. of spermatozoa } \\
\left(\times 10^{6}\right)\end{array}$ & TUNEL $(\%)$ \\
\hline \multicolumn{6}{|l|}{ Weight (kg) } \\
\hline Correlation & -0.271 & -0.235 & -0.213 & -0.211 & -0.231 \\
\hline $\mathrm{RC}$ & -4.3 & -4.1 & -3.8 & -3.1 & -4.0 \\
\hline$* P<$ & 0.002 & 0.003 & 0.009 & 0.001 & 0.002 \\
\hline \multicolumn{6}{|l|}{ BMI $\left(\mathrm{kg} / \mathrm{m}^{2}\right)$} \\
\hline Correlation & -0.138 & -0.149 & -0.126 & -0.108 & -0.189 \\
\hline $\mathrm{RC}$ & -1.6 & -1.7 & -1.2 & -0.8 & -1.9 \\
\hline$* P<$ & 0.005 & 0.003 & 0.002 & 0.029 & 0.002 \\
\hline \multicolumn{6}{|l|}{ Fat $(\%)$} \\
\hline Correlation & -0.215 & -0.206 & -0.188 & -0.195 & -0.198 \\
\hline $\mathrm{RC}$ & -3.4 & -2.1 & -1.1 & -0.8 & -1.0 \\
\hline$* P<$ & 0.002 & 0.006 & 0.019 & 0.025 & 0.009 \\
\hline \multicolumn{6}{|l|}{ WC $(\mathrm{cm})$} \\
\hline Correlation & -0.264 & -0.302 & -0.287 & -0.201 & -0.271 \\
\hline $\mathrm{RC}$ & -5.3 & -6.3 & -4.3 & -3.3 & -4.7 \\
\hline$* P<$ & 0.001 & 0.001 & 0.001 & 0.003 & 0.001 \\
\hline \multicolumn{6}{|c|}{$\mathrm{VO}_{2 \max }(\mathrm{mL} / \mathrm{kg} / \mathrm{min})$} \\
\hline Correlation & 0.143 & 0.167 & 0.122 & 0.137 & -0.215 \\
\hline $\mathrm{RC}$ & 1.4 & 2.1 & 1.4 & 1.1 & -2.5 \\
\hline$* P<$ & 0.002 & 0.001 & 0.019 & 0.002 & 0.001 \\
\hline \multicolumn{6}{|l|}{$\mathrm{SOD}(\mathrm{U} / \mathrm{mL})$} \\
\hline Correlation & 0.198 & 0.215 & 0.180 & 0.174 & 0.236 \\
\hline $\mathrm{RC}$ & 1.1 & 2.7 & 1.9 & 1.3 & 4.5 \\
\hline$* P<$ & 0.005 & 0.003 & 0.003 & 0.006 & 0.001 \\
\hline \multicolumn{6}{|c|}{ Catalase $(\mathrm{U} / \mathrm{mL})$} \\
\hline Correlation & 0.264 & 0.259 & 0.224 & 0.209 & 0.278 \\
\hline $\mathrm{RC}$ & 4.9 & 3.2 & 3.9 & 2.5 & 5.6 \\
\hline$* P<$ & 0.001 & 0.003 & 0.002 & 0.003 & 0.001 \\
\hline \multicolumn{6}{|l|}{ TAC (mM) } \\
\hline Correlation & 0.199 & 0.228 & 0.193 & 0.195 & 0.255 \\
\hline $\mathrm{RC}$ & 1.7 & 3.7 & 1.2 & 1.9 & 3.3 \\
\hline$* P<$ & 0.019 & 0.001 & 0.021 & 0.007 & 0.002 \\
\hline \multicolumn{6}{|l|}{ ROS (RLU) } \\
\hline Correlation & -0.241 & -0.264 & -0.216 & -0.198 & -0.249 \\
\hline $\mathrm{RC}$ & -3.1 & -3.3 & -2.1 & -1.8 & -2.4 \\
\hline$* P<$ & 0.002 & 0.001 & 0.003 & 0.016 & 0.003 \\
\hline \multicolumn{6}{|c|}{$\mathrm{MDA}(\mathrm{nmol} / \mathrm{mL})$} \\
\hline Correlation & -0.223 & -0.212 & -0.196 & -0.182 & -0.325 \\
\hline $\mathrm{RC}$ & -2.2 & -1.2 & -1.6 & -0.9 & -3.1 \\
\hline$* P<$ & 0.031 & 0.002 & 0.003 & 0.028 & 0.002 \\
\hline \multicolumn{6}{|c|}{ 8-Isoprostane (ng/mL) } \\
\hline Correlation & -0.194 & -0.183 & -0.167 & -0.126 & -0.284 \\
\hline $\mathrm{RC}$ & -0.9 & -1.7 & -1.3 & -0.8 & -2.7 \\
\hline$* P<$ & 0.014 & 0.029 & 0.002 & 0.036 & 0.008 \\
\hline \multicolumn{6}{|l|}{ IL-1 $\beta$ (pg/mL) } \\
\hline Correlation & -0.319 & -0.348 & -0.259 & -0.217 & -0.302 \\
\hline $\mathrm{RC}$ & -4.9 & -5.1 & -3.8 & -3.3 & -4.2 \\
\hline$* P<$ & 0.001 & 0.001 & 0.002 & 0.001 & 0.002 \\
\hline \multicolumn{6}{|l|}{ IL-6 (pg/mL) } \\
\hline Correlation & -0.283 & -0.251 & -0.219 & -0.161 & -0.296 \\
\hline $\mathrm{RC}$ & -2.6 & -2.2 & -1.2 & -1.1 & -3.6 \\
\hline$* P<$ & 0.002 & 0.003 & 0.002 & 0.027 & 0.004 \\
\hline \multicolumn{6}{|l|}{ IL-8 (pg/mL) } \\
\hline Correlation & -0.211 & -0.222 & -0.182 & -0.126 & -0.298 \\
\hline $\mathrm{RC}$ & -2.7 & -3.4 & -1.7 & -1.8 & -3.4 \\
\hline \multirow{2}{*}{\multicolumn{6}{|c|}{$\mathrm{TNF}-\alpha(\mathrm{pg} / \mathrm{mL})$}} \\
\hline & & & & & \\
\hline Correlation & -0.267 & -0.295 & -0.232 & -0.159 & -0.266 \\
\hline $\mathrm{RC}$ & -4.6 & -5.8 & -2.9 & -2.1 & -6.9 \\
\hline$* P<$ & 0.001 & 0.002 & 0.006 & 0.007 & 0.001 \\
\hline
\end{tabular}

${ }^{*} P<0.05$, adjusted for the group through the study based on mixed model. $\mathrm{RC}$, regression coefficient; WC, waist circumference.

a $4.7 \mathrm{~cm}$ reduction in waist circumference, a $2.4 \mathrm{RLU}$ reduction in ROS, a $3.1 \mathrm{nmol} / \mathrm{mL}$ reduction in MDA, a $2.7 \mathrm{ng} / \mathrm{mL}$ reduction in 8 -isoprostane, a $4.2 \mathrm{pg} / \mathrm{mL}$ reduction in $\mathrm{IL}-1 \beta$, a $3.6 \mathrm{pg} / \mathrm{mL}$ reduction in $\mathrm{IL}-6$, a $3.4 \mathrm{pg} / \mathrm{mL}$ reduction in $\mathrm{IL}-8$ and finally a $6.9 \mathrm{pg} / \mathrm{mL}$ reduction in TNF- $\alpha$ (Table 4). 
Significant positive correlations were also observed among progressive motility, sperm morphology, sperm concentration, number of spermatozoa and percentage of TUNEL-positive spermatozoa with SOD, catalase and TAC (Table 4). Each unit (\%) increase in progressive motility was associated with a $1.1 \mathrm{U} / \mathrm{mL}$ increase in $\mathrm{SOD}$, a $4.9 \mathrm{U} / \mathrm{mL}$ increase in catalase and finally a $1.7 \mathrm{nM}$ increase in TAC. Also, each unit (\%) increase in sperm morphology was associated with a $2.7 \mathrm{U} / \mathrm{mL}$ increase in SOD, a $3.2 \mathrm{U} / \mathrm{mL}$ increase in catalase and finally a $3.7 \mathrm{nM}$ increase in TAC. Similarly, each unit $\left(\times 10^{6}\right)$ increase in number of spermatozoa was associated with a $1.3 \mathrm{U} / \mathrm{mL}$ increase in SOD, a $2.5 \mathrm{U} / \mathrm{mL}$ increase in catalase and finally a $1.9 \mathrm{nM}$ increase in TAC (Table 4). Percentages of TUNEL-positive spermatozoa and $\mathrm{VO}_{2 \max }$ levels were negatively correlated, whereas positive correlations between $\mathrm{VO}_{2 \max }$ progressive motility, sperm morphology, sperm concentration and number of spermatozoa were noted. The mixedmodel regression showed that each unit increase in $\mathrm{VO}_{2 \max }$ levels resulted in $2.5 \%$ increase in percentages of TUNEL-positive spermatozoa, and each unit increase in $\mathrm{VO}_{2 \max }$ levels was associated with a $1.4 \%$ increase in progressive motility, a $2.1 \%$ increase in sperm morphology, a $1.4 \times 10^{6} / \mathrm{mL}$ increase in sperm concentration and finally a $1.1 \times 10^{6}$ increase in number of spermatozoa (Table 4).

\section{Discussion}

The results showed that 24 weeks of MICT, HICT and HIIT decreased seminal markers of oxidative stress and inflammation with different kinetics for the three types of exercise, and these changes were correlated with improvements in semen quality parameters and sperm DNA integrity in healthy human subjects. These data clearly show that MICT is superior to HICT and HIIT in the improvements of markers of male reproductive function, representing adaptation to moderate-intensity regular training.

To date, no reports have conducted to examine the seminal cytokines response to moderate-intensity aerobic exercise training. However, there is some evidence that aerobic exercise training is anti-inflammatory, and moderate-intensity aerobic exercise has been shown to attenuate the circulating markers of inflammation in both healthy and diseased populations (Tartibian et al. 2011, 2015, Abd El-Kader et al. 2013). Recently, a 3 -month randomized trial aerobic exercise training showed reduced plasma concentrations of TNF- $\alpha$, IL-2 and IL- 6 among obese type 2 diabetic patients (Abd El-Kader et al. 2013). Likewise, previous studies have also shown decreases in serum C-reactive protein (CRP), prostaglandin (PG) $E_{2}$, TNF- $\alpha$, IL- 6 and IL-8 levels with 16 and 24 weeks of moderate-intensity aerobic exercise training in postmenopausal women (Tartibian et al. 2011,
2015). Our results indicate that seminal IL-1 $\beta$, IL-6, IL-8 and TNF- $\alpha$ were significantly attenuated at both 12 and 24 weeks after MICT. However, in the HIIT group, significant alterations in seminal cytokines observed only after 24 weeks of the exercise intervention. Our data also show an improvement in seminal inflammatory mediators after $\mathrm{HICT}$ as reflected by significant decreases in IL- 6 and TNF- $\alpha$ at 24 weeks. It seems that MICT can elicit greater cytokine adaptations than HICT and HIIT. Reasons for this include improvements in seminal markers of inflammation that are more remarkable when exercise is performed at moderate intensities. Single bouts of intense exercise have been shown to induce systemic inflammatory responses similar to those associated with injury (Kaspar et al. 2016). However, evidence suggests that long-term exercise training reduces plasma inflammatory states (Homaee et al. 2014). The mechanisms by which exercise training attenuates seminal proinflammatory cytokines are still not fully understood; however, it is plausible that production of proinflammatory mediators induced by every single session of HICT and HIIT could be progressively reduced as confirmed by previous studies (Homaee et al. 2014). Moreover, it has been suggested that exercise training lowers resting proinflammatory mediators by upregulating the anti-inflammatory cytokine levels across body fluids, organs and tissues (Gleeson et al. 2006). So, the 24 weeks of training could have allowed enough time for the immune systems to reduce the acute elevation of each single session of highintensity training. Likewise, exercise-induced weight loss appears to lower levels of circulating cytokines, and the effect is greater with larger amounts of weight loss (Lambert et al. 2008). Therefore, in the present study, it seems exercise-induced changes in body composition (weight, $\mathrm{BMI}$, fat $\%$ and waist circumference) also mediated these effects. Our finding regarding the decrease in proinflammatory cytokines in the HICT group was somewhat unexpected because previous studies by our team have reported significant increases in seminal IL-1 $\beta$, IL-6, IL- 8 and TNF- $\alpha$ after chronic high-intensity cycling training in male road cyclists (Maleki et al. 2014, Hajizadeh Maleki \& Tartibian 2015). These discrepant findings may be due to the different training methods used to evaluate chronic cytokines responses to exercise training as well as different populations studied. The physiological and metabolic factors associated with cycling performance and factors inherent to cycling training, such as compression of the area by the bike saddle and the tight culottes worn, may be other possible contributing factors for these discrepant results. These data demonstrate that exercise training is effective in reducing seminal proinflammatory cytokines levels in healthy human subjects and indicate that the anti-inflammatory effect is dependent on the characteristics of exercise modalities, including volume, intensity and type. 
It is known that moderate-intensity aerobic training improves oxidative stress status in a wide range of body fluids, cells and/or tissues (Ennezat et al. 2001, Edwards et al. 2004, Linke et al. 2005). In samples of skeletal muscle and plasma, twelve weeks of moderateintensity aerobic exercise, for instance, has been shown to induce significant decreases in markers of oxidative stress and lipid peroxidation as well promote an upregulation in antioxidant defense, evident by an elevation in the activity of SOD, glutathione peroxidase and catalase (Ennezat et al. 2001, Edwards et al. 2004, Linke et al. 2005). Similar studies, in type 2 diabetics and obese individuals, reported a decrease in serum and plasma lipid peroxidation as well as an increase in glutathione and catalase activity after six months of moderate-intensity $\left(50-70 \% \mathrm{HR}_{\max }\right)$ aerobic exercise protocol (Lazarevic et al. 2006, Rector et al. 2007). In the present study, pro- and antioxidants measurements were not made in blood; however, relatively good correlations have previously been reported between systemic and seminal oxidative stress by other investigators (Shamsi et al. 2010, Benedetti et al. 2012). Our data are in agreement with these results as we observed significant attenuation in oxidative stress after exercise in the MICT group. In the present study, significant alterations in SOD, TAC and 8-isoprostane observed only after 24 weeks of MICT $\left(56-69 \% \mathrm{VO}_{2 \max }\right)$, but not after 12 weeks $\left(45-55 \% \mathrm{VO}_{2 \max }\right)$. In contrast, catalase, ROS and MDA changes were observed after 12 weeks of the intervention. Thus, the training duration and intensity seem to be important variables affecting these adaptations. These findings also raise the hypothesis that seminal markers of oxidative stress tend to respond differently to exercise intervention.

A trend toward reductions of resting seminal antioxidants including SOD, TAC and catalase as well as increases of oxidative stress markers, evident by an elevation in the seminal concentrations of ROS, MDA and 8-isoprostane, were shown in male road cyclists after chronic intensive cycling training $\left(\geq 82.9 \% \mathrm{VO}_{2 \max }\right)$ (Tartibian \& Maleki 2012b, Maleki et al. 2014, 2016b, Hajizadeh Maleki \& Tartibian 2015). Conversely, in the study by Miyazaki and coworkers, a 12-week strenuous endurance training (running at $80 \%$ maximal exercise heart rate for $60 \mathrm{~min} /$ day, 5 days/week) resulted in significant increases in resting SOD and GPX activities in erythrocytes. This upregulation in antioxidant defenses was also accompanied by a reduction in exercise-induced lipid peroxidation in erythrocyte membrane (Miyazaki et al. 2001). Our data have shown attenuation in oxidative stress only after 24 weeks of the HICT as reflected by a decrease in ROS levels as well as increases in SOD and catalase activities. The HICT intervention also induced positive but nonsignificant reductions in MDA and 8-isoprostane concentrations. This response seems to be affected by the training duration and intensity as there were no significant changes in these parameters at 12 weeks of the intervention in this group.

As for HIIT, the effects on seminal markers of oxidative stress are not well understood yet; however, our findings parallel previous reports that HIIT promotes antioxidant defense system (Tucker et al. 2015, Wadley et al. 2016) and decreases markers of oxidative stress in several tissue compartments in both healthy and diseased populations (Tucker et al. 2015, Wadley et al. 2016). Other investigators previously reported (Wadley et al. 2016) that HIIT was more effective at upregulating mRNA expression of renal SOD1 and catalase, compared to low-intensity exercise. However, in the present study, compared to HICT and HIIT, MICT induced significantly more profound effects on oxidant/ antioxidant markers in seminal plasma. This divergence could be explained, in part, by the diversity of protocols implemented (training methods, protocol duration, training volume, age of participants, etc.), tissue-specific oxidative stress responses and the individual responses of each subject. In addition, improvements in seminal oxidative status were apparent in HIIT compared to HICT, as HIIT intervention resulted in marked changes in seminal TAC and MDA than those seen in the HICT group. Mechanisms responsible for beneficial effects of chronic exercise on redox balance are traininginduced upregulation of antioxidant enzymes, reduced mitochondrial ROS production and increase in radical scavenging capacity of body tissues and fluids (Finaud et al. 2006, Gomes et al. 2012). Exerciseinduced upregulation of the antioxidant defense in the HICT and HIIT groups may also explain the observed reductions in seminal markers of oxidative stress in these groups. However, one should bear in mind that, although the ROS family induces oxidative damages when the balance between the generation of ROS and the capacity of antioxidation systems to eliminate them is disturbed, in recent years, also a significant number of research studies have documented a role of ROS as second messengers of cell signaling responsible for the prevention of diseases either by provoking antioxidant response (Meilhac et al. 2001) or other adaptations to exercise via activating useful cellular redox-sensitive signaling pathways (Gomez-Cabrera et al. 2005, Ji 2007, Kang et al. 2009). Exercise-induced ROS may therefore serve also as signaling molecules to enhance the expression of cytoprotective proteins and to preserve some other normal physiological functions (Li 2013).

Seminal markers of oxidative stress and inflammation have been linked to sperm function and DNA integrity (Sanocka et al. 2003, Fraczek et al. 2008, Fraczek \& Kurpisz 2015). Oxidative stress in seminal plasma have been associated with negative changes in sperm concentration, motility and morphology (Khosrowbeygi \& Zarghami 2007, Agarwal et al. 2014) and can cause potential damage to the plasma membrane of the sperm cell and DNA integrity (Tremellen 2008), leading to poor 
semen quality and sperm dysfunction. Elevated levels of IL-1 $\beta$, IL-6, IL-8 and TNF- $\alpha$ in seminal plasma have also been demonstrated as the factors linked with a decrease in number of spermatozoa, progressive motility, sperm morphology as well as sperm vitality (Fraczek \& Kurpisz 2015). These cytokines may adversely affect sperm cell function and the reproductive process (Sanocka et al. 2003, Fraczek et al. 2008, Fraczek \& Kurpisz 2015). The redox imbalance is probably the major etiological factor responsible for the destructive effects of proinflammatory cytokines on sperm DNA integrity (Sanocka et al. 2003, Fraczek et al. 2008).

Our results indicate that progressive motility, sperm morphology, sperm concentration and number of spermatozoa were significantly elevated at both 12 and 24 weeks after MICT.

In addition to the enhancement of semen quality, our data show an improvement in semen volume and sperm DNA integrity after MICT as reflected by a decrease in percentages of TUNNEL-positive spermatozoa at 24 weeks. Several studies (Tartibian \& Maleki 2012a, Hajizadeh Maleki et al. 2013) have reported that low-tomoderate-intensity recreational physical activities causes an improvement in semen parameters as well as sperm DNA integrity than either vigorous-intensity physical activities or sedentary life style. It has been proposed that low-to-moderate-intensity recreational physical activity-induced adaptations in seminal antioxidant defense system mediated these effects (Tartibian \& Maleki 2012a, Hajizadeh Maleki et al. 2013). Our data confirm and extend these findings as we observed positive correlations among semen quality parameters, sperm DNA integrity and antioxidants. Seminal markers of oxidative stress also were significantly negatively associated with sperm DNA integrity and semen quality parameters.

Additionally, significant increases in progressive motility, sperm morphology, sperm concentration as well as marked decreases in percentages of TUNELpositive spermatozoa observed only after 24 weeks of both HICT and HIIT interventions, but not after 12 weeks. We could not find any research papers that investigated the impact of HICT on male reproductive function; however, based on findings of reduced semen quality in long-distance runners and endurance cyclists, several studies have reported detrimental effects of strenuous exercise on male reproductive function (De Souza et al. 1994, Miller et al. 1997, Safarinejad et al. 2009, Tartibian \& Maleki 2012b, Maleki et al. 2014, 2016b, Hajizadeh Maleki \& Tartibian 2015). Increased percentages of TUNEL-positive spermatozoa were also observed in male road cyclists after intensive cycling training (Maleki et al. 2016b). The authors suggested that this increase may be due to either exercise-induced oxidative stress or increased intrascrotal temperature produced mainly by the bike saddle and the tight clothes worn during long rides in male road cyclists
(Maleki et al. 2016b). Different training methods and different assessment parameters as well as different groups of subjects were involved may contribute to the inconsistent findings in the present study. In this study, improved sperm DNA integrity after HIIT intervention are consistent with Vezzoli and coworkers who investigated the effect of 8 weeks of high-intensity discontinuous training (at $120-140 \% \mathrm{VO}_{2 \text { peak }}$ ) on 8-hydroxy-2-deoxyguanosine $(8-\mathrm{OH}-\mathrm{dG})$ as a biomarker of DNA base modifications in long-distance runners and showed a decrease $(\sim 25 \%)$ in urinary $8-\mathrm{OH}-\mathrm{dG}$ excretion after exercise (Vezzoli et al. 2014). These findings may be influenced by increases in endogenous antioxidant status, upregulation of antioxidant capacity, increase in radical scavenging capacity of spermatozoa or seminal plasma as well as upregulation in DNA damagerepairing enzymes after participation in HICT and HIIT interventions. In addition, the results confirmed that attenuation of seminal proinflammatory cytokines with chronic exercise is associated with improvements in semen quality and DNA integrity in this cohort of healthy subjects, which is consistent with previous reports (Sanocka et al. 2003, Fraczek \& Kurpisz 2007, 2015, Fraczek et al. 2008, Tartibian \& Maleki 2012b, Hajizadeh Maleki et al. 2013, Maleki et al. 2014, Hajizadeh Maleki \& Tartibian 2015). These findings are important to the fields of exercise science and reproductive function because they provide substantial evidence regarding the immunological and oxidative stress responses of human semen to physical exercise. Though all exercise modalities induced significant alterations in semen quality parameters and sperm DNA integrity, the changes were more pronounced in the MICT group than those observed in the HICT and HIIT groups. This current investigation also presents evidence for intensity- and duration-dependent alterations in semen quality parameters and sperm DNA integrity after different exercise modalities, as these variables changed exponentially in relation to exercise intensity and duration. Therefore, the magnitude and extent of semen parameters and DNA integrity responses to physical exercise seem to be associated with characteristics of exercise intervention such as type, intensity and duration.

Also, it should be pointed out that, although the allotted time was substantially higher for the HICT group, there was no increased benefit. Thus, with the fewer number and lower duration of exercise sessions as those in the HICT group, subjects in the HIIT group achieved the same or even better improvements in markers of male reproductive function, changes that can greatly influence male reproductive health and functions. This indicates that the short high-intensity stimuli (on average $85 \%$ of $\left.\mathrm{VO}_{2 \max }\right)$ were effective in provoking a better response than that of a HICT at $70-85 \%$ of $\mathrm{VO}_{2 \max }$.

In addition, the results confirmed that decreases in weight, $\mathrm{BMI}$, fat $\%$ and waist circumference are 
associated with improvements in semen quality parameters and sperm DNA integrity, which is consistent with previous reports (Kort et al. 2006, Kriegel et al. 2009). Reviewed elsewhere, research has substantiated the inverse relationship between body composition and male reproductive potential (Kort et al. 2006, Kriegel et al. 2009). There is some evidence that excessive body fat in men reduces sperm concentration (Kort et al. 2006), sperm motility (Kort et al. 2006) and sperm morphology (Kriegel et al. 2009). Despite the use of a variety of different methodologies to measure sperm DNA integrity, several human studies have also demonstrated that a relationship exists between obesity and reduced sperm DNA integrity (Kort et al. 2006, Kriegel et al. 2009). In the present investigation also respectively, negative and positive correlations were found between $\mathrm{VO}_{2 \max }$ with percentages of TUNEL-positive spermatozoa and semen quality parameters. Although the exact mechanisms by which improvements in cardiorespiratory fitness benefits male reproductive potential are not clear yet, several lines of evidence have correlated post-exercise alterations in $\mathrm{VO}_{2 \max }$, among others, to improved body composition measures (leanmass:fat-mass) (Casla et al. 2015). Therefore, in the present study, post-exercise improvements in semen quality and sperm DNA integrity are likely related, in part, to the effects of exercise training on measures of body composition and cardio-respiratory fitness.

This study is limited mainly by the difference in volume and total work performed. Future studies may want to verify whether volume- and work-matched MICT, HICT and HIIE exhibit different reproductive responses. However, to the best of our knowledge, this is the first study in which three different exercise modalities have been compared before and after training with a control group, with respect to the markers of male reproductive function in healthy human subjects.

In conclusion, the present study adds to this body of evidence and shows seminal markers of inflammation and oxidative stress improved significantly after 24 weeks of MICT, HICT or HIIT; and these changes were correspond with favorable improvements in semen quality parameters and sperm DNA integrity. These results further indicate that MICT was more beneficial in improving markers of male reproductive function, compared to HICT and HIIT. These observations suggest that the intensity, duration and type of exercise training could be taken into consideration when investigating reproductive responses to exercise training in men. It remains to be determined how changes in seminal markers of male reproductive function may be connected with reproductive outcomes in healthy human subjects.

\section{Declaration of interest}

The authors declare that there is no conflict of interest that could be perceived as prejudicing the impartiality of the research reported.

\section{Funding}

This research did not receive any specific grant from any funding agency in the public, commercial or not-for-profit sector.

\section{Acknowledgements}

The authors are grateful to the subjects who participated in the study for without their dedication, the study could not have been carried out.

\section{References}

Abd El-Kader S, Gari A \& Salah El-Den A 2013 Impact of moderate versus mild aerobic exercise training on inflammatory cytokines in obese type 2 diabetic patients: a randomized clinical trial. African Health Sciences 13 857-863. (doi:10.4314/ahs.v13i4.1)

Aebi H 1984 Catalase in vitro. Methods in Enzymology 105 121-126. (doi:10.1016/s0076-6879(84)05016-3)

Agarwal A, Virk G, Ong C \& du Plessis SS 2014 Effect of oxidative stress on male reproduction. World Journal of Men's Health 32 1-17. (doi:10.5534/wjmh.2014.32.1.1)

Aitken RJ, Baker MA, De Iuliis GN \& Nixon B 2010 New insights into sperm physiology and pathology. Handbook of Experimental Pharmacology 198 99-115. (doi:10.1007/978-3-642-02062-9_7)

Benedetti S, Tagliamonte MC, Catalani S, Primiterra M, Canestrari F, De Stefani S, Palini S \& Bulletti C 2012 Differences in blood and semen oxidative status in fertile and infertile men, and their relationship with sperm quality. Reproductive BioMedicine Online 25 300-306. (doi:10.1016/j.rbmo.2012.05.011)

Bruce R, Blackmon J, Jones J \& Strait G 1963 Exercising testing in adult normal subjects and cardiac patients. Pediatrics $32742-756$.

Casla S, Lopez-Tarruella S, Jerez Y, Marquez-Rodas I, Galvao DA, Newton RU, Cubedo R, Calvo I, Sampedro J, Barakat R et al. 2015 Supervised physical exercise improves VO2max, quality of life, and health in early stage breast cancer patients: a randomized controlled trial. Breast Cancer Research and Treatment 153 371-382. (doi:10.1007/ s10549-015-3541-x)

De Iuliis GN, Wingate JK, Koppers AJ, McLaughlin EA \& Aitken RJ 2006 Definitive evidence for the nonmitochondrial production of superoxide anion by human spermatozoa. Journal of Clinical Endocrinology and Metabolism 91 1968-1975. (doi:10.1210/jc.2005-2711)

De Souza MJ, Arce JC, Pescatello LS, Scherzer HS \& Luciano AA 1994 Gonadal hormones and semen quality in male runners. A volume threshold effect of endurance training. International Journal of Sports Medicine 15 383-391. (doi:10.1055/s-2007-1021075)

Edwards DG, Schofield RS, Lennon SL, Pierce GL, Nichols WW \& Braith RW 2004 Effect of exercise training on endothelial function in men with coronary artery disease. American Journal of Cardiology 93 617-620. (doi:10.1016/j.amjcard.2003.11.032)

Ennezat PV, Malendowicz SL, Testa M, Colombo PC, Cohen-Solal A, Evans T \& LeJemtel TH 2001 Physical training in patients with chronic heart failure enhances the expression of genes encoding antioxidative enzymes. Journal of the American College of Cardiology 38 194-198. (doi:10.1016/S0735-1097(01)01321-3)

Finaud J, Lac G \& Filaire E 2006 Oxidative stress: relationship with exercise and training. Sports Medicine 36 327-358. (doi:10.2165/00007256200636040-00004) 
Fraczek M \& Kurpisz M 2007 Inflammatory mediators exert toxic effects of oxidative stress on human spermatozoa. Journal of Andrology 28 325-333. (doi:10.2164/jandrol.106.001149)

Fraczek M \& Kurpisz M 2015 Cytokines in the male reproductive tract and their role in infertility disorders. Journal of Reproductive Immunology 108 98-104. (doi:10.1016/j.jri.2015.02.001)

Fraczek M, Sanocka D, Kamieniczna M \& Kurpisz M 2008 Proinflammatory cytokines as an intermediate factor enhancing lipid sperm membrane peroxidation in in vitro conditions. Journal of Andrology 29 85-92. (doi:10.2164/jandrol.107.003319)

Gaskins AJ, Mendiola J, Afeiche M, Jorgensen N, Swan SH \& Chavarro JE 2015 Physical activity and television watching in relation to semen quality in young men. British Journal of Sports Medicine 49 265-270. (doi:10.1136/bjsports-2012-091644)

Gleeson M, McFarlin B \& Flynn M 2006 Exercise and Toll-like receptors. Exercise Immunology Review 12 34-53.

Gomes EC, Silva AN \& de Oliveira MR 2012 Oxidants, antioxidants, and the beneficial roles of exercise-induced production of reactive species. Oxidative Medicine and Cellular Longevity 2012756132. (doi:10.1155/2012/756132)

Gomez-Cabrera MC, Borrás C, Pallardó FV, Sastre J, Ji LL \& Viña J 2005 Decreasing xanthine oxidase-mediated oxidative stress prevents useful cellular adaptations to exercise in rats. Journal of Physiology $\mathbf{5 6 7}$ 113-120. (doi:10.1113/jphysiol.2004.080564)

Gorczyca W, Gong J \& Darzynkiewicz Z 1993 Detection of DNA strand breaks in individual apoptotic cells by the in situ terminal deoxynucleotidyl transferase and nick translation assays. Cancer Research 53 1945-1951.

Hajizadeh Maleki B \& Tartibian B 2015 Long-term low-to-intensive cycling training: impact on semen parameters and seminal cytokines. Clinical Journal of Sport Medicine 25 535-540.

Hajizadeh Maleki B, Tartibian B, Eghbali M \& Asri-Rezaei S 2013 Comparison of seminal oxidants and antioxidants in subjects with different levels of physical fitness. Andrology 1 607-614. (doi:10.1111/ j.2047-2927.2012.00023.x)

Homaee HM, Moradi L, Azarbayjani MA \& Peeri M 2014 Effect of high intensity exercise training (HIIT) and endurance training on weight loss and C-reactive protein in obese men. International Journal of Biosciences 4 190-196.

Ji LL 2007 Antioxidant signaling in skeletal muscle: a brief review. Experimental Gerontology 42 582-593. (doi:10.1016/j. exger.2007.03.002)

Kang C, O'Moore KM, Dickman JR \& Ji LL 2009 Exercise activation of muscle peroxisome proliferator-activated receptor- $\gamma$ coactivator- $1 \alpha$ signaling is redox sensitive. Free Radical Biology and Medicine 47 1394-1400. (doi:10.1016/j.freeradbiomed.2009.08.007)

Kaspar F, Jelinek HF, Perkins S, Al-Aubaidy HA, deJong B \& Butkowski E 2016 Acute-phase inflammatory response to single-bout HIIT and endurance training: a comparative study. Mediators of Inflammation 20165474837.

Khosrowbeygi A \& Zarghami N 2007 Levels of oxidative stress biomarkers in seminal plasma and their relationship with seminal parameters. BMC Clinical Pathology 7 6. (doi:10.1186/1472-6890-7-6)

Kort HI, Massey JB, Elsner CW, Mitchell-Leef D, Shapiro DB, Witt MA \& Roudebush WE 2006 Impact of body mass index values on sperm quantity and quality. Journal of Andrology 27 450-452. (doi:10.2164/ jandrol.05124)

Kriegel TM, Heidenreich F, Kettner K, Pursche T, Hoflack B, Grunewald S, Poenicke K, Glander HJ \& Paasch U 2009 Identification of diabetesand obesity-associated proteomic changes in human spermatozoa by difference gel electrophoresis. Reproductive BioMedicine Online 19 660-670. (doi:10.1016/j.rbmo.2009.07.001)

Lambert CP, Wright NR, Finck BN \& Villareal DT 2008 Exercise but not diet-induced weight loss decreases skeletal muscle inflammatory gene expression in frail obese elderly persons. Journal of Applied Physiology (1985) 105 473-478. (doi:10.1152/ japplphysiol.00006.2008)

Lazarevic G, Antic S, Cvetkovic T, Vlahovic P, Tasic I \& Stefanovic V 2006 A physical activity programme and its effects on insulin resistance and oxidative defense in obese male patients with type 2 diabetes mellitus. Diabetes and Metabolism 32 583-590. (doi:10.1016/S12623636(07)70312-9)
Li G 2013 The Positive and Negative Aspects of Reactive Oxygen Species in Sports Performance, Current Issues in Sports and Exercise Medicine. Ed M Hamlin. InTech. (Available at: http://www.intechopen.com/ books/current-issues-in-sports-and-exercise-medicine/the-positive-andnegative-aspects-of-reactive-oxygen-species-in-sports-performance). (doi:10.5772/53360)

Linke A, Adams V, Schulze PC, Erbs S, Gielen S, Fiehn E, MobiusWinkler S, Schubert A, Schuler G \& Hambrecht R 2005 Antioxidative effects of exercise training in patients with chronic heart failure: increase in radical scavenger enzyme activity in skeletal muscle. Circulation 111 1763-1770. (doi:10.1161/01.CIR.0000165503.08661.E5)

Mahfouz RZ, Sharma RK, Poenicke K, Jha R, Paasch U, Grunewald S \& Agarwal A 2009a Evaluation of poly(ADP-ribose) polymerase cleavage (CPARP) in ejaculated human sperm fractions after induction of apoptosis. Fertility and Sterility 91 2210-2220. (doi:10.1016/j. fertnstert.2008.02.173)

Mahfouz RZ, Sharma RK, Said TM, Erenpreiss J \& Agarwal A 2009b Association of sperm apoptosis and DNA ploidy with sperm chromatin quality in human spermatozoa. Fertility and Sterility 91 1110-1118. (doi:10.1016/j.fertnstert.2008.01.047)

Maleki BH, Tartibian B \& Vaamonde D 2014 The effects of 16 weeks of intensive cycling training on seminal oxidants and antioxidants in male road cyclists. Clinical Journal of Sport Medicine 24 302-307. (doi:10.1097/JSM.0000000000000051)

Maleki BH, Tartibian B, Mooren FC, Krüger K, FitzGerald LZ \& Chehrazi M 2016a A randomized controlled trial examining the effects of 16 weeks of moderate-to-intensive cycling and honey supplementation on lymphocyte oxidative DNA damage and cytokine changes in male road cyclists. Cytokine 88 222-231. (doi:10.1016/j.cyto.2016.09.016)

Maleki BH, Tartibian B, Mooren FC, Nezhad FY \& Yaseri M 2016b Saffron supplementation ameliorates oxidative damage to sperm DNA following a 16-week low-to-intensive cycling training in male road cyclists. Journal of Functional Foods 21 153-166. (doi:10.1016/j.jff.2015.11.048)

Martinez P, Proverbio F \& Camejo MI 2007 Sperm lipid peroxidation and pro-inflammatory cytokines. Asian Journal of Andrology 9 102-107. (doi:10.1111/j.1745-7262.2007.00238.x)

Meilhac O, Ramachandran S, Chiang K, Santanam N \& Parthasarathy S 2001 Role of arterial wall antioxidant defense in beneficial effects of exercise on atherosclerosis in mice. Arteriosclerosis, Thrombosis, and Vascular Biology 21 1681-1688. (doi:10.1161/hq1001.097106)

Meucci E, Milardi D, Mordente A, Martorana GE, Giacchi E, De Marinis L \& Mancini A 2003 Total antioxidant capacity in patients with varicoceles. Fertility and Sterility 79 (Supplement 3) 1577-1583. (doi:10.1016/ S0015-0282(03)00404-7)

Miller BE, Hackney AC \& De Souza MJ 1997 The endurance training on hormone and semen profiles in marathon runners. Fertility and Sterility 67 585-586; author reply 586-587. (doi:10.1016/S0015-0282(97)80096-9)

Miyazaki H, Oh-ishi S, Ookawara T, Kizaki T, Toshinai K, Ha S, Haga S, Ji LL \& Ohno H 2001 Strenuous endurance training in humans reduces oxidative stress following exhausting exercise. European Journal of Applied Physiology 84 1-6. (doi:10.1007/s004210000342)

Moein MR, Dehghani VO, Tabibnejad N \& Vahidi S 2007 Reactive Oxygen Species (ROS) level in seminal plasma of infertile men and healthy donors. Iranian Journal of Reproductive Medicine 5 51-55.

Naz RK \& Kaplan P 1994 Increased levels of interleukin-6 in seminal plasma of infertile men. Journal of Andrology 15 220-227.

Nonaka-Sarukawa M, Yamamoto K, Aoki H, Takano H, Katsuki T, Ikeda U \& Shimada K 2003 Increased urinary 15-F2t-isoprostane concentrations in patients with non-ischaemic congestive heart failure: a marker of oxidative stress. Heart 89 871-874. (doi:10.1136/heart.89.8.871)

Oh S, Tanaka K, Warabi E \& Shoda J 2013 Exercise reduces inflammation and oxidative stress in obesity-related liver diseases. Medicine and Science in Sports and Exercise 45 2214-2222. (doi:10.1249/ MSS.0b013e31829afc33)

Politch JA, Tucker L, Bowman FP \& Anderson DJ 2007 Concentrations and significance of cytokines and other immunologic factors in semen of healthy fertile men. Human Reproduction 22 2928-2935. (doi:10.1093/ humrep/dem281)

Rector RS, Warner SO, Liu Y, Hinton PS, Sun GY, Cox RH, Stump CS, Laughlin MH, Dellsperger KC \& Thomas TR 2007 Exercise and diet induced weight loss improves measures of oxidative stress and insulin sensitivity in adults with characteristics of the metabolic syndrome. 
American Journal of Physiology: Endocrinology and Metabolism 293 E500-E506. (doi:10.1152/ajpendo.00116.2007)

Safarinejad MR, Azma K \& Kolahi AA 2009 The effects of intensive, longterm treadmill running on reproductive hormones, hypothalamuspituitary-testis axis, and semen quality: a randomized controlled study. Journal of Endocrinology 200 259-271. (doi:10.1677/JOE-08-0477)

Said TM, Kattal N, Sharma RK, Sikka SC, Thomas AJ Jr, Mascha E \& Agarwal A 2003 Enhanced chemiluminescence assay vs colorimetric assay for measurement of the total antioxidant capacity of human seminal plasma. Journal of Andrology 24 676-680. (doi:10.1002/j.1939-4640.2003. tb02726.x)

Sanocka D, Jedrzejczak P, Szumala-Kaekol A, Fraczek M \& Kurpisz M 2003 Male genital tract inflammation: the role of selected interleukins in regulation of pro-oxidant and antioxidant enzymatic substances in seminal plasma. Journal of Andrology 24 448-455. (doi:10.1002/j.1939-4640.2003.tb02693.x)

Shamsi MB, Venkatesh S, Kumar R, Gupta NP, Malhotra N, Singh N, Mittal S, Arora S, Arya DS, Talwar P et al. 2010 Antioxidant levels in blood and seminal plasma and their impact on sperm parameters in infertile men. Indian Journal of Biochemistry and Biophysics 47 38-43.

Shara MA, Dickson PH, Bagchi D \& Stohs SJ 1992 Excretion of formaldehyde, malondialdehyde, acetaldehyde and acetone in the urine of rats in response to 2,3,7,8-tetrachlorodibenzo-p-dioxin, paraquat, endrin and carbon tetrachloride. Journal of Chromatography $\mathbf{5 7 6}$ 221-233. (doi:10.1016/0378-4347(92)80196-W)

Soares JP, Silva AM, Oliveira MM, Peixoto F, Gaivao I \& Mota MP 2015 Effects of combined physical exercise training on DNA damage and repair capacity: role of oxidative stress changes. Age 379799. (doi:10.1007/s11357-015-9799-4)

Tartibian B \& Maleki BH 2012a Correlation between seminal oxidative stress biomarkers and antioxidants with sperm DNA damage in elite athletes and recreationally active men. Clinical Journal of Sport Medicine 22 132-139. (doi:10.1097/JSM.0b013e31823f310a)

Tartibian B \& Maleki BH 2012b The effects of honey supplementation on seminal plasma cytokines, oxidative stress biomarkers, and antioxidants during 8 weeks of intensive cycling training. Journal of Andrology 33 449-461. (doi:10.2164/jandrol.110.012815)

Tartibian B, Maleki BH, Kanaley J \& Sadeghi K 2011 Long-term aerobic exercise and omega-3 supplementation modulate osteoporosis through inflammatory mechanisms in post-menopausal women: a randomized, repeated measures study. Nutrition and Metabolism 81. (doi:10.1186/1743-7075-8-1)

Tartibian B, Maleki BH, Abbasi A, Eghbali M, Asri-Rezaei S \& Northoff H 2012 Comparison of Seminal Superoxide Dismutase (SOD) Activity Between Elite Athletes, Active and Non Active Men, An International Perspective on Topics in Sports Medicine and Sports Injury. Ed Kenneth
R Zaslav. InTech. (Available at: http://www.intechopen.com/books/ an-international-perspective-on-topics-in-sports-medicine-and-sportsinjury/comparison-of-seminal-superoxide-dismutase-sod-activitybetween-elite-athletes-active-and-non-active). (doi:10.5772/25664)

Tartibian B, FitzGerald LZ, Azadpour N \& Maleki BH 2015 A randomized controlled study examining the effect of exercise on inflammatory cytokine levels in post-menopausal women. Post Reproductive Health 21 9-15. (doi:10.1177/2053369114565708)

Tremellen K 2008 Oxidative stress and male infertility - a clinical perspective. Human Reproduction Update 14 243-258. (doi:10.1093/ humupd/dmn004)

Tucker PS, Briskey DR, Scanlan AT, Coombes JS \& Dalbo VJ 2015 High intensity interval training favourably affects antioxidant and inflammation mRNA expression in early-stage chronic kidney disease. Free Radical Biology and Medicine 89 466-472. (doi:10.1016/j. freeradbiomed.2015.07.162)

Vezzoli A, Pugliese L, Marzorati M, Serpiello FR, La Torre A \& Porcelli S 2014 Time-course changes of oxidative stress response to highintensity discontinuous training versus moderate-intensity continuous training in masters runners. PLOS ONE 9 e87506. (doi:10.1371/journal. pone.0087506)

Wadley AJ, Chen YW, Lip GY, Fisher JP \& Aldred S 2016 Low volumehigh intensity interval exercise elicits antioxidant and anti-inflammatory effects in humans. Journal of Sports Sciences 34 1-9. (doi:10.1080/026 40414.2015.1035666)

Wise LA, Cramer DW, Hornstein MD, Ashby RK \& Missmer SA 2011 Physical activity and semen quality among men attending an infertility clinic. Fertility and Sterility 95 1025-1030. (doi:10.1016/j. fertnstert.2010.11.006)

World Health Organization 2010 WHO Laboratory Manual for the Examination and Processing of Human Semen, 5th ed. UK: Cambridge University Press.

Yousefniapasha Y, Jorsaraei G, Gholinezhadchari M, Mahjoub S, Hajiahmadi M \& Farsi M 2015 Nitric oxide levels and total antioxidant capacity in the seminal plasma of infertile smoking men. Cell Journal 17 129-136.

Zini A, Fischer MA, Mak V, Phang D \& Jarvi K 2002 Catalase-like and superoxide dismutase-like activities in human seminal plasma. Urological Research 30 321-323. (doi:10.1007/s00240-002-0283-0)

Received 13 June 2016

First decision 19 September 2016

Revised manuscript received 2 November 2016

Accepted 10 November 2016 